\title{
Numerical Simulation of Concussive-generated Cortical Spreading Depolarization to Optimize EEG Electrode Spacing for Non-invasive Detection
}

Samuel J. Hund, PhD ${ }^{1,2}$

Benjamin R. Brown, $\mathrm{PhD}^{1}$

Coline L. Lemale, MSc ${ }^{3,4}$

Prahlad G. Menon, PhD ${ }^{1,5}$

Kirk A. Easley, MS, MApStat ${ }^{6}$

Jens P. Dreier, MD ${ }^{3,4,7,8,9}$

Stephen C. Jones, $\mathrm{PhD}^{1^{*}}$

${ }^{1}$ CerebroScope, the dba entity of SciencePlusPlease LLC, 1936 Fifth Avenue, Floor 2, Unit 2, Pittsburgh, PA 15219-5544, USA

2 SimulationSolutions, LLC, 5707 Jackson St., Pittsburgh, PA, 15206, USA

${ }^{3}$ Center for Stroke Research, Charité - Universitätsmedizin Berlin, corporate member of Freie Universität Berlin, Humboldt-Universität zu Berlin, and Berlin Institute of Health, Berlin, Germany

${ }^{4}$ Department of Experimental Neurology, Charité - Universitätsmedizin Berlin, corporate member of Freie Universität Berlin, Humboldt-Universität zu Berlin, and Berlin Institute of Health, Berlin, Germany

${ }^{5}$ Previous address:

Electrical \& Computer Engineering, SYSU-CMU Joint Institute of Engineering, Sun Yat-sen University - Carnegie Mellon University (SYSU-CMU), 5000 Forbes Ave., Pittsburgh, PA, 15213, USA

Current address:

Department of Bioengineering, University of Pittsburgh, 302 Benedum Hall, Ohara St., Pittsburgh, PA, 15213, USA

${ }^{6}$ Department of Biostatistics and Bioinformatics, Rollins School of Public Health, Emory University, 1518 Clifton Road NE, Atlanta, GA, 30322, USA

${ }^{7}$ Department of Neurology, Charité - Universitätsmedizin Berlin, corporate member of Freie Universität Berlin, Humboldt-Universität zu Berlin, and Berlin Institute of Health, Berlin, Germany

${ }^{8}$ Bernstein Center for Computational Neuroscience Berlin, Berlin, Germany

${ }^{9}$ Einstein Center for Neurosciences Berlin, Berlin, Germany

Word count: 6204 words

Number of Figures: 6 (plus one supplemental movie and one supplemental figure)

Number of Tables: 2

* Correspondence:

Stephen C. Jones

CerebroScope, the dba entity of SciencePlusPlease LLC

1936 Fifth Avenue, Floor 2, Unit 2

Pittsburgh, PA 15219-5544, USA

ph: 412-208-3397

sjones@cerebro-scope.com 
Hund et al. Scalp detection of cortical spreading depolarization from concussion Page 2 of 49

\section{Abstract}

Background: Cortical Spreading Depolarization (SD) is a propagating depolarization wave of neurons and glial cells in the cerebral gray matter. SD occurs in all forms of severe acute brain injury as documented using invasive detection methods. Based on many experimental studies of mechanical brain deformation and concussion, the occurrence of SDs in human concussion has often been hypothesized. However, this hypothesis cannot be confirmed in humans as SDs can only be detected with invasive detection methods that would require either a craniotomy or a burr hole to be performed on athletes. Typical electroencephalography (EEG) electrodes, placed on the scalp, can detect the possible presence of SD but have not been able to accurately and reliably identify SDs.

Methods: To explore the possibility of a non-invasive method to resolve this hurdle, we developed a finite element numerical model that simulates scalp voltage changes that are induced by a brain-surface SD. We then compared our simulation results with retrospectively evaluated data in aneurysmal subarachnoid hemorrhage (aSAH) patients from Drenckhahn et al. (Brain 135:853, 2012).

Results: The ratio of peak scalp to simulated peak cortical voltage, Vscalp/Vcortex, was 0.0735, whereas the ratio from the retrospectively evaluated data was $0.0316(0.0221,0.0527)$ [median ( $1^{\text {st }}$ quartile, $3^{\text {rd }}$ quartile), $\mathrm{n}=161, \mathrm{p}<0.001$, one sample Wilcoxon signed rank test]. This difference can be attributed to differences in shape between concussive- and aSAH-SDs, as well as the inherent limitations in human study voltage measurements. This simulated scalp surface 
Hund et al. Scalp detection of cortical spreading depolarization from concussion Page 3 of 49

potential was used to design a virtual scalp detection array. Error analysis and visual reconstruction showed that $1 \mathrm{~cm}$ is the optimal electrode spacing to visually identify and track the propagating scalp voltage from a cortical SD. Electrode spacing greater than $1.5 \mathrm{~cm}$ produces distorted images and unacceptable errors in velocity and dimensions.

Conclusion: Our analysis suggests that concussive (and other) SDs can be detected from the scalp, which could confirm SD occurrence in human concussion, provide concussion diagnosis based on an underlying physiological mechanism, and lead to non-invasive SD detection in the setting of severe acute brain injury.

Keywords: full-band EEG; DC-EEG; Cortical Spreading Depolarization; Brain Concussion; Mild Traumatic Brain Injury; Finite Element Analysis; Numerical Simulation; Electroencephalography, Electrocorticography; Concussion detection; Non-invasive 
Hund et al. Scalp detection of cortical spreading depolarization from concussion Page 4 of 49

\section{Introduction}

Concussion, also known as mild traumatic brain injury (not to be confused with severe traumatic brain injury), affects 1.6-3.8 million individuals per year in the United States [1-3], and the actual number is likely higher because of underreporting and misdiagnosis [4]. In particular, sports concussion has garnered major public attention in recent years [5-9]. Concussions during military [10-12], automotive, occupational, and bicycle accidents have increasingly added to the public consciousness. Diagnosis of concussion depends on highly variable and often non-specific symptoms that include physical, cognitive, behavioral, emotional, and sleep-related aspects [13]. Immediate diagnostic methods rely on psychometric, reaction time, and balance assessments, but the accuracy, reliability, and repeatability of these assessments have come into question [14-21]. Health professionals typically test for potential sports-related concussions during the acute phase using the Sport Concussion Assessment Tool 5th Edition, SCAT 5, [22], which includes many of the aforementioned components. The assessment of acute concussion to prevent serious consequences of inappropriate return-to-play decisions $[23,24]$ is a well-established process that is based on multiple symptoms but without an underlying pathophysiological mechanism.

The historical [25] and emerging experimental [26] evidence that concussion is accompanied by cortical Spreading Depolarization (SD) suggest that SD might be the underlying cause of, or at the least contribute to, acute concussion symptomatology in the immediate minutes after concussion. Currently, diffuse axonal injury (DAI) is the most widely accepted anatomical mechanism accounting for the acute and chronic symptoms of concussion. DAI has been proposed as an objective diagnostic criteria based on axonal pathophysiology assessed by MRI and the increased blood concentration of axonal proteins [27]. However, the effects of DAI

Copyright $\odot 2021$ All rights reserved, CerebroScope, the dba of SciencePlusPlease LLC

Published under a Creative Commons Attribution-NonCommercial-NoDerivatives 4.0 International (CC BY-NC-ND) 4.0 International License (http://creativecommons.org/licenses/by-nc-nd/4.0/).

CSDSp-bioRxiv-wFigures\&SupplementalMaterial_210408.doc, scj, 4/8/2021 12:45 PM, ps1/ 49 
Hund et al. Scalp detection of cortical spreading depolarization from concussion Page 5 of 49

and SD are separated both by where they occur anatomically, with DAI affecting axons and SD occurring in neurons and glia, and the timing of their effects. Concussion is thought to induce a brain network dysfunction, in which white matter damage and DAI are implicated in characteristic symptoms such as slowed information processing at one day [28] and five years [29], post-concussion, time periods which are not relevant to the immediate occurrence of SD following concussion.

\subsection{What are SDs?}

SDs are regions ( $\sim \mathrm{mm}$ width or diameter) of large amplitude direct-current (DC, $5-30 \mathrm{mV}$ ) negative en mass depolarization of neuronal and glial cells in gray matter that persist over several minutes [30-34]. The hallmark of SD is the near-complete breakdown of the neuronal transmembrane ion gradients [35] that leads to influx of water and cytotoxic edema [36]. Secondarily, glutamate is released in large amounts [37]. SDs are slow-moving waves (1 - 9 $\mathrm{mm} / \mathrm{min}$ ) that lead to depression of electroencephalographic (EEG) amplitudes for 0.5 - 3 minutes, with normal function grossly restored after 5 - 10 minutes if the vasculature is not compromised [38-40]. Although SDs were originally discovered in rabbits in the 1940s [39], it was not until the 1990s that they were initially observed in a single severe acute brain trauma patient [41]. In the early 2000s, Strong and colleagues presented the first robust bedside method that used subdural electrodes to detect SDs in approximately 50\% of individuals with traumatic brain injury [33].

SDs occur abundantly in severe acute brain injury, including malignant hemispheric stroke, subarachnoid hemorrhage (SAH), spontaneous intracerebral hemorrhage, and severe traumatic brain injury [38, 42-47]. The transition from long-lasting SDs in severely ischemic 
Hund et al. Scalp detection of cortical spreading depolarization from concussion Page 6 of 49

tissue to short-lasting SDs in less ischemic or normal tissue has been described as "the SD continuum” [48, 49]. Terminal SDs during the development of stroke, brain death and death from circulatory arrest represent the extreme end of the SD continuum [31, 50-55]. In addition, short-lasting SD in otherwise healthy tissue is assumed to be the underlying cause of migraine aura [32, 56, 57], which is the only clinical manifestation of SD in which the wave-like nature of SD becomes clinically apparent, leading to the fallacy for many decades that migraine aura is the only clinical manifestation of SD [48]. In the first phase of ischemic strokes due to arterial occlusion, and most likely in concussion, the SD spreads concentrically from the ischemic core [58] or the point of impact [39]. The consequences of SD occurrence in both migraine and concussion, if it does occur in human concussion, are temporary, in stark contrast to the “continuum” pathological role of SD in severe acute brain injury [48].

\subsection{Rationale for SD Occurring in Concussion}

SD and concussion were first linked by observation that a firm, non-damaging touch of the brain elucidated an SD [39]. This initial observation of brain deformation causing SD was the basis for extensive studies using controlled brain deformation [59-61]. These studies of brain deformation were not focused on human concussion but rather the mechanical parameters of brain deformation, including the speed, area, and depth of the depression that elicited SD. The direct link between concussion and SD was suggested based on a comparison of the energies required to elicit SD and experimental concussion [62]. This comparison is weakened by concern that: 1) the calculation of energies was not described or referenced; 2) only experimental, non-human studies provided evidence; and 3) the rate of deformation, a parameter that determines SD initiation, was not used. These concerns make the presumption that human concussion is always 
Hund et al. Scalp detection of cortical spreading depolarization from concussion Page 7 of 49

accompanied by SD a hypothesis that needs testing.

Many experimental studies have noted the similar features of concussion and SD, including high metabolic rate [63] and high $\left[\mathrm{K}^{+}\right]_{0}$ [64]. In particular, EEG suppression [65-67] and negative DC-potential [67] in experimental models of concussion were consistent with the original observations of EEG suppression [39] and negative DC-potential during SD [34].

Studies demonstrating the presence of SD in mouse models of concussion strongly suggest that SD might be a common feature of concussion [26, 68]. The behavioral effects associated with SD after controlled cortical impact without craniotomy are similar to the diverse symptoms used to diagnose human concussion [26]. All of these experimental studies used models of concussion that excluded cerebral contusion or intra-cranial hematomas.

Several clinical studies [69, 70] and reviews [71-73] have presented compelling arguments suggesting that SD could explain concussion symptomatology. Although this experimental and clinical evidence that a blow to the cranium could trigger SD is scientifically valid, the mechanism of SD initiation by brain deformation has not been explored and the electrophysiological confirmation of this scenario in humans [25; page 1083] is missing.

\subsection{Mechanisms of Mechanical Brain Deformation Induced SD}

Although the mechanisms of SD initiation and propagation have been extensively explored [25, 74], there has been no attention devoted to the mechanism of SD elicited by brain deformation. Strangely, brain deformation has been ascribed to many modes of eliciting SD, as thoroughly described by Marshall [75], including pinprick, pledget application of compounds that elicit SD to the cortical surface, neurosurgical procedures that involve brain deformation or compression, and others. However, many studies have been performed using in vitro models of neuronal 
Hund et al. Scalp detection of cortical spreading depolarization from concussion Page 8 of 49

stretch that show both permeability and ion channel changes [76, 77] whose time scale is relevant to concussive SD initiation. In this same time scale, there is evidence that cells do partially depolarize after stretch due to permeability increases $[78,79]$. These issues could be explored for their connection to the mechanism of SD generation by brain deformation. A recent study suggests spontaneous SDs in an “intracortical hemorrhage model are triggered by the mechanical distortion of tissue by rapidly growing hematomas” [80].

To explore the possibility of non-invasive detection methods that might resolve the conundrum between the scientific evidence for, and missing confirmation of, SD in human concussion, we performed a numerical simulation to model the spatial and temporal characteristics, as well as the magnitude, of the scalp DC-voltage from an assumed brain-surface concussive SD. We then compared the computational model with retrospectively evaluated human results from aneurysmal SAH (aSAH) patients, given that human concussion data are not available. Finally, we used this simulated scalp DC-potential to investigate the ideal spatial configuration of an electrode sensor array for scalp DC-EEG detection of SD.

Our hypotheses are that our simulated scalp DC-potential: 1) compares with existing experimental data; 2) can be used to determine the electrode configuration necessary for accurate non-invasive SD detection; and 3) is consistent with the detection limits of DC-EEG. The implications of these hypotheses are that if propagating SDs can be noninvasively detected, concussion detection using SD is possible, the role of SD in concussion could be explored, and noninvasive SD detection in severe acute brain injury patients might be possible.

Copyright $\odot 2021$ All rights reserved, CerebroScope, the dba of SciencePlusPlease LLC

Published under a Creative Commons Attribution-NonCommercial-NoDerivatives 4.0 International (CC BY-NC-ND) 4.0 International License (http://creativecommons.org/licenses/by-nc-nd/4.0/).

CSDSp-bioRxiv-wFigures\&SupplementalMaterial_210408.doc, scj, 4/8/2021 12:45 PM, ps1/ 49 
Hund et al. Scalp detection of cortical spreading depolarization from concussion Page 9 of 49

\section{Methods}

\subsection{DC-EEG Forward Problem using a Finite Element Model}

Various authors have conducted numerical simulations of EEG phenomena in the brain and head directed both at the forward problem [81] and inverse source localization [82, 83]. Most models focused on the number of tissue layers and geometry [81, 82, 84-87] but others have been concerned with material properties and constitutive equations [88-90]. However, all these models used clinical EEG frequencies greater than $0.5 \mathrm{~Hz}$, except for the inverse source localization effort by Miller et al. [83] which used frequencies of 0 to $70 \mathrm{~Hz}$ in contrast to the clinical frequency range. Our forward problem simulation is unique as it deals with the near-zero frequencies of the SD's brain-surface DC-potential using DC-EEG. To implement our simulation, we first mathematically describe the brain-surface SD voltage waveform, then the characteristics of the layers between the brain surface and the scalp, and finally, the boundary conditions at the scalp.

\subsection{SD Waveform}

The voltage and current density of an SD at the brain surface were calculated in the tissue using a conductive medium model:

$$
-\nabla \bullet\left[\left(\sigma+\varepsilon_{o} \varepsilon_{r} \frac{\partial}{\partial t}\right) \nabla V\right]=Q,
$$

where $\mathrm{t}$ is time, $\sigma$ is the conductivity, $\varepsilon_{\mathrm{o}}$ is the permittivity in a vacuum, $\varepsilon_{\mathrm{r}}$ is the relative permittivity, $\mathrm{V}$ is voltage potential, and $\mathrm{Q}$ is a source term. The cortex was not modeled as the SD spreads along the cortical surface and is instead implemented into the model with the boundary condition: 
Hund et al. Scalp detection of cortical spreading depolarization from concussion Page 10 of 49

$$
V_{\text {cortex }}=\Delta V_{S D} \chi(r, t) \text {, }
$$

where $\Delta \mathrm{V}_{\mathrm{SD}}$ is the cortical surface voltage potential of $\mathrm{SD}(-20 \mathrm{mV})$ and $\chi$ is a shape function describing the spatio-temporal behavior of the spreading, namely an expanding ring with a thickness or width of $3 \mathrm{~mm}$ and a velocity of $3 \mathrm{~mm} / \mathrm{min}$ appearing 0 - $40 \mathrm{~s}$ after impact $[39,40]$. Two different shape functions were used to describe the SD, whose initial inner radius is zero at the concussive focus.

The first shape function is a square wave:

$$
\chi(r, t)=\left\{\begin{array}{cc}
1 & r_{\text {inner }} \leq r \leq r_{\text {outer }} \\
0 & \text { elsewhere }
\end{array}\right.
$$

where $r$ is the distance from the focus of the concussion. The radius of the ring expands outward

as:

$$
r(t)=\frac{W}{2}+v_{C S D} t
$$

where $\mathrm{W}$ is the constant ring thickness of the wave $(3 \mathrm{~mm})$, and $\mathrm{v}_{\mathrm{SD}}$ is the propagation speed of the SD (3 mm/min). The inner (trailing) edge of the ring, $\mathrm{r}_{\mathrm{inner}}$, and outer (leading) edge of the ring, $\mathrm{r}_{\text {outer }}$, are then

$$
\begin{aligned}
& r_{\text {inner }}=r(t)-\frac{W}{2}, \text { and } \\
& r_{\text {outer }}=r(t)+\frac{W}{2} .
\end{aligned}
$$


Hund et al. Scalp detection of cortical spreading depolarization from concussion Page 11 of 49

The second shape function is a triangular wave:

$$
\chi(r, t)=\left\{\begin{array}{cc}
\frac{r-r_{\text {inner }}}{r(t)-r_{\text {inner }}} & r_{\text {inner }} \leq r \leq r(t) \\
\frac{r_{\text {outer }}-r}{r_{\text {outer }}-r(t)} & r(t)<r \leq r_{\text {outer }}, \\
0 & \text { elsewhere }
\end{array}\right.
$$

where $r(t)$ is the radius of the expanding ring, and $r_{\text {inner }}$ and $r_{\text {outer }}$ are again the inner and outer radii of the ring. These two shapes bracket the largest and smallest transmission of signal to the scalp (or most optimistic and least optimistic signal estimates) for a given $\mathrm{SD}$ voltage, $\Delta \mathrm{V}_{\mathrm{SD}}$, and width, W.

\subsection{Layers and Thicknesses}

A five-layer model was used for this project, focusing on 1) cerebrospinal fluid (CSF); 2) dura matter; 3) skull; 4) muscle; and 5) skin (see Fig. 1b). Ramon et al. [82] showed that the CSF was the major factor in a quality model. The total thickness is $1.02 \mathrm{~cm}$ and the thickness of each layer can be found in Table 1 . The values for layer thickness, relative permittivity (dielectric constant), and conductance, as presented in Table 1, were obtained from various literature sources [81, 82, 90-92]. The frontal bone of the skull was chosen as the reference because this is the area where athletic concussions are most likely to occur, and it is also the thickest part of the skull on average, resulting in the greatest attenuation of the signal [93]. Furthermore, the results will be compared to clinical research data collected by Drenckhahn et al. [31] for SDs occurring primarily in the frontal cortex of aSAH patients (see below for details). Instead of relying on a multilayer model of the skull, i.e., hard and soft bone [81, 94-96], the theory of interacting 
Hund et al. Scalp detection of cortical spreading depolarization from concussion Page 12 of 49

continua was used to determine the parameters through mixture theory [97].

\subsection{Scalp Surface Characterization}

The boundary condition for the scalp was zero normal current density. Furthermore, no current sources (Q) were used; however, Q can be used to produce noise and additional signal generation such as that of the transdermal epithelial potential (TEP) or the galvanic skin potential. The model ignores the TEP, i.e., assumes the skin is abraded $[98,99]$.

\subsection{Simulation Details and Parameters}

The simulation was performed on a cylindrical domain with a radius of $10 \mathrm{~cm}$ (see Fig. 1a and 1c). This radius was chosen to be large to prevent interference effects of the boundary condition. Due to the slow propagation velocity of SDs, the total time simulated was 15 minutes. The simulation was performed using COMSOL 4.3 (COMSOL, Inc.) with a structured hexagonal mesh, which uses an adaptive time solver with a relative error below 1e-6. The spatial resolution of the mesh was evaluated using the grid convergence index (GCI) method, which is the American Society of Mechanical Engineers standard [100]. The mesh element sizes were 0.886, 0.481, and $0.246 \mathrm{~mm}$ for the coarse, medium, and fine meshes, respectively. The coarse mesh had some elements with GCI qualities as low as 0.4 ( $<10 \%$ of elements) and the fine mesh elements all had quality values above 0.95; all elements had GCI qualities above the level of concern (0.1). Furthermore, the simulation was validated against an analytical solution for a constant voltage drop of $20 \mathrm{mV}$ applied between the scalp and the cortex. The layer resistances, $\mathrm{R}$, can be calculated as:

$$
R=\frac{h}{A \sigma}
$$

Copyright $\odot 2021$ All rights reserved, CerebroScope, the dba of SciencePlusPlease LLC

Published under a Creative Commons Attribution-NonCommercial-NoDerivatives 4.0 International (CC BY-NC-ND) 4.0 International License (http://creativecommons.org/licenses/by-nc-nd/4.0/).

CSDSp-bioRxiv-wFigures\&SupplementalMaterial_210408.doc, scj, 4/8/2021 12:45 PM, ps1/ 49 
Hund et al. Scalp detection of cortical spreading depolarization from concussion Page 13 of 49

where $\mathrm{h}$ is the thickness and A the cross-sectional area of the layer. The current and voltage drop can then be calculated from Ohm's law. The resulting errors were less than 3e-7 mA and $1 \mathrm{e}-5 \mathrm{mV}$ for current and voltage, respectively, between the closed-form solution and the numerical results.

The shape of the potential of the SD as it propagates through the various layers was characterized through a relative voltage, $\mathrm{V}_{\text {rel }}$ :

$$
V_{r e l}=\frac{V_{i}}{\min \left(V_{i}\right)}
$$

which compares the voltage of the $i^{\text {th }}$ layer, $V_{i}$, to the minimum voltage on that layer occurring between the time of 5 and 15 minutes, $\min \left(V_{i}\right)$. A value of 0.2 was set for the threshold of $V_{\text {rel }}$ in order to determine the thickness or width of the SD-based DC-potential and to tag times for analyzing sensor data.

\subsection{Retrospective Evaluation of Human Data [31]}

We retrospectively evaluated the amplitude of SDs in three aSAH patients with sufficient quality subdural full-band ECoG (fbECoG) and scalp full-band EEG (fbEEG) recordings from Drenckhahn et al. [31]. Patient recruitment and characteristics, fbEEG and fbECoG recording, data processing and analysis are detailed in Drenckhahn et al. [31]. Research protocols were approved by the institutional review board and surrogate informed consent was obtained for all patients. All research was conducted in accordance with the Declaration of Helsinki.

In brief, a single, linear, six-contact (platinum) recording strip (Wyler, 5 mm diameter; Ad-Tech Medical) was placed on the surface of the cortex for ECoG recordings [33, 42, 43]. Both fbECoG and fbEEG recordings were performed (bandpass: 0-1000 Hz, sampling rate: 2500 $\mathrm{Hz}$ ) using a BrainAmp amplifier. The electrodes were attached with Collodion adhesive 
Hund et al. Scalp detection of cortical spreading depolarization from concussion Page 14 of 49

(Mavidon) after abrasive electrode gel (Abralyt 2000, EasyCap) and conductive electrode cream (Synapse, Med-Tek) were applied to minimize electrode impedance $(<5 \mathrm{kV})$ and ensure longterm stability of the signal. Data were recorded and reviewed with the use of LabChart 7 software (ADInstruments) and BrainVision Recorder 1.05 software (Brain Products), respectively. For each pair of subdural fbECoG and scalp fbEEG recordings from the same SD, the maximum voltage of each was recorded. The ratio of these subdural and scalp voltages was compared with the ratio determined from our simulation.

\subsection{Simulated Scalp Detector Construction}

The scalp surface signal over a $10 \mathrm{~cm}$ x $10 \mathrm{~cm}$ square was modeled from simulated electrode readings by sampling the predicted voltages at various electrode spacings. Results are shown for a SD centered at $2.5 \mathrm{~cm}$ from the left of the center of the sensor array. The relative location of the sensor grid to the simulation domain and focal point of the SD can be seen in Fig. 1a. Figure 1d shows a sample grid with 1-cm spacing. The root-mean-squared error (or the L2 norm),

$$
\left\|V_{n}(x, y)-V_{0.5}(x, y)\right\|_{L 2}=\int_{\Omega}\left(V_{n}(x, y)-V_{0.5}(x, y)\right)^{2} d \Omega,
$$

where $\Omega$ is the domain, was used to compare the error between the voltage reconstruction at 0.5mm electrode spacing $\left(\mathrm{V}_{0.5}\right)$ and the other arrays with electrode spacing of $1,5,10,15,20,25$, 30, 40, and $50 \mathrm{~mm}\left(\mathrm{~V}_{\mathrm{n}}\right)$. The reconstruction was also performed by averaging the voltage potential over circular areas $(0.5,0.75,1,1.5,2,2.5,3,4$, and $5 \mathrm{~mm}$ radii) representing various sizes of the active area of the electrode. Results were compared with the infinitesimal or point values of voltage.

Copyright $\odot 2021$ All rights reserved, CerebroScope, the dba of SciencePlusPlease LLC

Published under a Creative Commons Attribution-NonCommercial-NoDerivatives 4.0 International (CC BY-NC-ND) 4.0 International License (http://creativecommons.org/licenses/by-nc-nd/4.0/).

CSDSp-bioRxiv-wFigures\&SupplementalMaterial_210408.doc, scj, 4/8/2021 12:45 PM, ps1/ 49 
Hund et al. Scalp detection of cortical spreading depolarization from concussion Page 15 of 49

\subsection{Errors Due to Detection Array Offset}

A second study, independent of the regular grid study above, was performed to understand how different offsets (see Fig. 1e) influenced SD velocity calculations from the simulated scalp data. To simplify this error analysis, a subset of the full electrode array was used composed of a linear electrode array. Errors in the velocity of the SD will occur if a linear sensor array is not aligned with the velocity field, which occurs for a concentrically expanding wave when the sensors are offset from a given radius. Therefore, velocity and ring thickness calculations were performed for a 1 x 7 array of electrodes with the sensor array situated so that the first electrode is located over the focus of the SD, and then with 3 additional linear 2 x 7 arrays that were separated by 0.1, 0.5, and $1 \mathrm{~cm}$. All arrays had an electrode spacing of $0.5 \mathrm{~cm}$ and length of $3 \mathrm{~cm}$ (see Fig. 1e). An apparent velocity, $v_{\text {app }}$, was calculated using the formula:

$$
v_{\text {app }}=\frac{D_{\text {sensor }}}{t_{i+1}-t_{i}},
$$

where $D_{\text {sensor }}$ is the spacing between two electrodes and $t_{i}$ is the time at which $V_{\text {rel }}$ of the $i^{\text {th }}$ electrode either first exceeds (onset) or is first restored below the threshold of 0.2 (abatement). Velocities were calculated using each electrode pair ( $i$ and $i+1)$, with the first pair consisting of the two electrodes closest to the focus and so forth. A scalp depolarization time $\left(t_{d}\right)$, where the threshold value was exceeded, was defined to be the time between onset and abatement. The scalp ring thickness $\left(\mathrm{W}_{\mathrm{s}}\right)$ was calculated using the equation:

$$
W_{s}=\frac{t_{d}}{v_{a p p}} .
$$

For this second study, the expanding ring SD was simulated with a velocity of $3 \mathrm{~mm} / \mathrm{min}$, a ring thickness of $30.8 \mathrm{~mm}$, and a depolarization time of 10.3 minutes.

Copyright $\odot 2021$ All rights reserved, CerebroScope, the dba of SciencePlusPlease LLC

Published under a Creative Commons Attribution-NonCommercial-NoDerivatives 4.0 International (CC BY-NC-ND) 4.0 International License (http://creativecommons.org/licenses/by-nc-nd/4.0/).

CSDSp-bioRxiv-wFigures\&SupplementalMaterial_210408.doc, scj, 4/8/2021 12:45 PM, ps1/ 49 
Hund et al. Scalp detection of cortical spreading depolarization from concussion Page 16 of 49

\subsection{Statistics}

Statistical tests were performed using SAS/STAT version 15.1 (SAS institute Inc, Cary, NC). A nonparametric statistical test was used because the voltage ratio measurements deviated significantly from a normal distribution. The one sample Wilcoxon signed rank test was used to compare our simulation derived voltage ratio with the voltage ratio determined from data retrospectively extracted from the work of Drenckhahn et al. [31]. Data are reported as medians ( $1^{\text {st }}$ quartile, $3^{\text {rd }}$ quartile) and $\mathrm{p}<0.05$ was accepted as statistically significant.

\section{Results}

The simulation results for the voltage and current density distributions in the various layers from the cortex to the scalp for a cortical triangular wave after 5 seconds and 10 minutes are shown in Fig. 2. The voltage field and ring shape at the interface between each layer of the model starting at the cortex and continuing to the scalp are summarized in Table 2. Early in the migration of the voltage depression, the voltage requires more time to return to rest after passage of the wave peak when compared to later time points. On the scalp, the relative voltage exceeded the 0.2 threshold at $14.6 \mathrm{~mm}$ ahead of the peak voltage and remained elevated $16.2 \mathrm{~mm}$ behind the peak value. Figures $2 \mathrm{~b}$ and $2 \mathrm{~d}$ show that the largest current densities occur in the first layer composed of CSF, as it is the most conductive, peaking at $35.6 \mathrm{~mA} / \mathrm{m}^{2}$ at the point of peak voltage on the cortical surface and weakening to below $2.1 \mathrm{~mA} / \mathrm{m}^{2}$ at locations $2 \mathrm{~mm}$ before and after the value of SD radius, $\mathrm{r}(\mathrm{t})$, at the peak cortical voltage. The muscle tissue also shows an elevated current density $\left(20 \mathrm{~mA} / \mathrm{m}^{2}\right)$, though much smaller than that in the CSF.

\subsection{Voltage Decrease}

The voltage detectable at the scalp is attenuated to 0.0735 of its strength at the cortex as shown

Copyright $\odot 2021$ All rights reserved, CerebroScope, the dba of SciencePlusPlease LLC

Published under a Creative Commons Attribution-NonCommercial-NoDerivatives 4.0 International (CC BY-NC-ND) 4.0 International License (http://creativecommons.org/licenses/by-nc-nd/4.0/).

CSDSp-bioRxiv-wFigures\&SupplementalMaterial_210408.doc, scj, 4/8/2021 12:45 PM, ps1/ 49 
Hund et al. Scalp detection of cortical spreading depolarization from concussion Page 17 of 49

in Table 2. The voltage is attenuated through each layer, while the affected region grows larger.

The largest amplitude drop, $\Delta \mathrm{V}=8.18 \mathrm{mV}$, occurs in the skull. A drop of 5.10 and $5.01 \mathrm{mV}$ occurred in the CSF and dura matter, respectively. The total voltage amplitude drop across the skin and muscle taken together was only $0.240 \mathrm{mV}$. Figure 3 compares the voltage at the cortex to that of the scalp, and at each interface between layers.

\subsection{Dimensional Changes}

The area above the threshold voltage grew most in the skull (595\%) and least in the muscle (0.74\%). The thickness of the voltage ring was $2.4 \mathrm{~mm}$ at the cortical surface and increases to $30.8 \mathrm{~mm}$ (x 12.8) at the scalp. There is also a spatial lag between the locations of the peak voltage on the cortex and the scalp of $0.474 \mathrm{~mm}$, which corresponds to a time delay of 0.16 minutes. Supplemental Movie S1 presents a movie of the scalp voltage from a cortical SD with both top and side views.

\subsection{Voltage Ratios from the Simulated Square and Triangle Waves}

This study investigated two types of propagation waves: a square wave and a triangular wave. Their peak voltages from the scalp electrode sampling results were noticeably different: $\mathrm{V}_{\text {peak }}$ was 3.6 and $1.47 \mathrm{mV}$ for the square and triangle waves, respectively, giving relative voltages of 0.18 and 0.0735 .

In addition to simulating the scalp signal with tissues having electromagnetic properties as measured in Penn and Bell [91], we also simulated the triangle wave profile with tissue having properties as reported by Gabriel et al. [92] (Table 1). Though the estimates of these parameters were different, some by several orders of magnitude, the resulting peak scalp voltage ratio was 
Hund et al. Scalp detection of cortical spreading depolarization from concussion Page 18 of 49

0.09, as opposed to 0.0735 , suggesting that signal detectability at the scalp is not sensitive to the variation of tissue properties between (or within) subjects.

\subsection{Voltage Ratio Comparison with Clinical Research Results}

We compared the voltage ratio from our simulation results with the voltage ratio retrospectively evaluated from the data collected by Drenckhahn et al. [31]. Paired and identifiable fbECoG subdural and fbEEG scalp recordings were available for 161 SDs. In the pooled analysis, the maximum fbECoG subdural peak amplitude among all electrodes for each individual SD was -9.3 (-7.2, -10.1) $\mathrm{mV}$. In the scalp fbEEG recordings of the same SDs, the maximum peak amplitude among all electrodes was $-273(-376,-176) \mu \mathrm{V}$. The ratio of peak scalp to peak subdural voltage was $0.0316(0.0221,0.0527)$ in the pooled data analysis $(n=161)$. The simulation results differed from the retrospectively evaluated data; the ratio of peak scalp to simulated peak cortical voltage, Vscalp/Vcortex $=0.0735$ versus $0.0316(0.0221,0.0527), \mathrm{n}=$ 161, $\mathrm{p}<0.001$, one sample Wilcoxon signed rank test].

\subsection{Effect of Electrode Spacing on Visualization of Scalp Voltage}

Figure 4 shows the reconstruction of the surface signal using regularly spaced sensor arrays with varying separation distance. The voltage reconstructions are visually consistent with the true field up to a sensor grid spacing of $1.0 \mathrm{~cm}$. At larger electrode grid spacings of $1.5-2.5 \mathrm{~cm}$, a breakdown of the ring structure occurs, and at even greater spacings the structure could not be discerned. Figure 5 illustrates how the loss of structure occurs due to the change in grid spacing. In this example, the electrodes on one diagonal are located on the ring of the SD (depressed voltage) and the other diagonal is on the normal tissue (baseline voltage), which results in the development of a notch, thus breaking the ring structure. Supplemental Fig. S1 shows the 
Hund et al. Scalp detection of cortical spreading depolarization from concussion Page 19 of 49

dependence of the degradation of the true scalp voltage on the electrode spacing and the time after SD initiation.

\subsection{Effect of Electrode Spacing on the Error in the Reconstruction of Scalp}

\section{Voltage}

Figure 6 shows the root-mean-squared error of the reconstructed scalp voltage as a function of electrode spacing. The error approaches 5\% for electrode spacing of $1.5 \mathrm{~cm}$ and increases to $25 \%$ for electrode spacing above $2.5 \mathrm{~cm}$. When taking into account differences in possible electrode diameter from 0.1 to $1 \mathrm{~cm}$, we found that the reconstructions only varied by $2 \%$ even when comparing a point electrode to one that was $1 \mathrm{~cm}$ in diameter. The error in reconstructing the brain-surface field from an electrode grid could be further reduced by application of more complex and computationally expensive methods.

The simulation allowed the characteristic parameters of SD to be estimated from the simulated scalp potential, but as previously noted, errors were dependent on a misalignment of the strip electrode and the origin and path of the spreading wave. The velocity and ring thickness predictions were dependent on the sensor offset from the velocity vector, as well as on the proximity to the focus of the SD.

\subsection{Error in Velocity}

The velocity was consistently over predicted. The error in the velocity calculation (in relation to the simulation velocity of $3 \mathrm{~mm} / \mathrm{min})$ using the onset time $\left(\mathrm{V}_{\text {rel }}\right.$ exceeding 0.2$)$ was highest near the focal point of the concussion, being 127\%, 127\%, 117\%, and $284 \%$ for the 4 different offsets, and decreasing to $7.5 \%, 6.4 \%, 8.7 \%$, and $19 \%$ for the final electrode pairing, i.e., the two electrodes furthest from the focus of the SD. The errors in the velocity calculation were smaller 
Hund et al. Scalp detection of cortical spreading depolarization from concussion Page 20 of 49

using the abatement times ( $\mathrm{V}_{\text {rel }}$ returns to less than 0.2$)$ with two electrodes closest to the focus predicting errors of $82 \%, 82 \%, 88.7 \%$, and $122 \%$, but the velocity errors were similar at the final electrode pairing to those predicted using the onset time.

The average time of electrode activation for $\mathrm{V}_{\text {rel }}>0.2$ was $9.66(9.12,9.9)$ minutes excluding electrodes for which the wave did not completely pass within the 15-minute time frame. The error in ring thickness increased as the array was offset; the error between predicted and actual thickness was $3.51 \%$ to $9.8 \%$ for the zero and $1 \mathrm{~cm}$ offset arrays, respectively.

\section{Discussion}

We simulated the scalp voltage produced by a concentrically traveling SD on the cortex of the brain and estimated that an electrode spacing of $1.0 \mathrm{~cm}$ is required to accurately collect the spatio-temporal data of the SD. The results showed that the SD wave detectability is dependent on electrode grid spacing, with loss of structure as grid spacing increases. The ratio of simulated peak scalp to peak cortical voltage $($ Vscalp/Vcortex $=0.0735)$ was approximately double compared to the retrospectively evaluated clinical research observations of Drenckhahn et al. [31]. This difference is presumably due to differences in SD shape and configuration between concussive and aSAH SDs. Although the amplitude from the simulated concussive SD is diminished to $\sim 7 \%$ of that at the brain surface through resistive dissipation, it is large enough to be detected by current DC-coupled amplifiers. The spatial expansion of negative DC-potential at the scalp of a brain-surface SD, which occurs mostly in the skull (low current but high resistance), aids in the non-invasive detection of a SD as it enlarges the ring thickness at the scalp.

Copyright $\odot 2021$ All rights reserved, CerebroScope, the dba of SciencePlusPlease LLC

Published under a Creative Commons Attribution-NonCommercial-NoDerivatives 4.0 International (CC BY-NC-ND) 4.0 International License (http://creativecommons.org/licenses/by-nc-nd/4.0/).

CSDSp-bioRxiv-wFigures\&SupplementalMaterial_210408.doc, scj, 4/8/2021 12:45 PM, ps1/ 49 
Hund et al. Scalp detection of cortical spreading depolarization from concussion Page 21 of 49

\subsection{Existing Methods of SD Detection}

The current method for detecting and measuring SDs using electrocorticography (ECoG) with strip electrodes directly placed on the cortical surface [33, 45] is invasive. This method is only used on patients where the electrodes are placed concurrently with a prior necessitated craniotomy or a burr hole trepanation for placement of a ventricular drain or oxygen sensor [101] as performed for the planning of resective epilepsy surgery [102; see section 'Burr Holes for Placement of Strip Electrodes (4th page) and Figure 4]. Often, publications using ECoG SD detection highlight the lack of a scalp detection method to reliably detect SD non-invasively [32, $101]$.

\subsection{Previous Non-Invasive Detection Attempts}

To answer this need for non-invasive SD detection, there have been two efforts directed at scalp SD detection using simultaneous ECoG at the cortical surface and EEG at the scalp with clinically-based electrode positions [31, 103]. Stationary residual negative scalp DC voltages between $65 \mu \mathrm{V}$ and $1 \mathrm{mV}$ associated with propagating SDs using ECoG have been measured on the scalp by Drenckhahn et al. [31]; however, SD propagation was not observed on the scalp (see Fig. 1A, traces 1-3 and 10-12, in Drenckhahn et al. [31]). The widened DC-potential at the scalp shown by our simulation is possibly the reason Drenckhahn et al. [31] observed that the scalp DC-voltage surface appeared at multiple electrodes simultaneously.

In another study, scalp observations of EEG suppression and DC-potential changes in patients whose bone-flap had been removed (except for 1 of 18 subjects) were guided by ECoGdetected SDs. However, unguided scalp SD detection was not established [103]. A replication of 
Hund et al. Scalp detection of cortical spreading depolarization from concussion Page 22 of 49

this study [104] and a follow-up rebuttal [105] did not provide evidence of unguided noninvasive SD detection.

Our simulation results were highly accurate (peak errors < 1e-3\%) when compared to the closed-form solutions. This accuracy suggests that imaging principles that were used in this work could be applied to detection and tracking of SDs. Therefore, systematic errors due to a simplified geometry, uniform thickness, and variations in material properties (conductivity and relative permittivity) will not significantly detract from the accuracy and reliability of the simulated data for its potential use in future designs.

\subsection{Velocity and Size Errors Using Estimates from a Limited Electrode Array}

The relative position of the SD focus and the electrode array affect the prediction of the size and speed of the SD. Electrodes nearest to the focal point of the SD showed the most significant errors in the velocity calculation ( $>100 \%)$. This is because directly above the focus, the scalp voltage is affected by the entire ring. This effect becomes less pronounced as the ring expands outwards. The apparent velocity approaches the expansion velocity of the SD as the leading edge (scalp) propagates away from the focal point (temporally and spatially). Electrodes further from the focus had relatively small errors ( 6\%) but increased (by 20\%) as the electrode-sensor row was offset from the radial projection of the SD focus. Despite the large variability in velocity predictions, the thickness of the SD was more reliably calculated with errors of approximately 4 $10 \%$ or $0.2-1.0 \mathrm{~cm}$. The model showed that the post-SD scalp voltage recovered at a slower rate due to the same axisymmetric influence of the ring structure with the more closely spaced electric field lines at the trailing edge of the ring. This sustains the decrease voltage of the depolarization for a longer duration $\left(t_{d}\right)$ at this trailing edge. These effects may not be indicative

Copyright $\odot 2021$ All rights reserved, CerebroScope, the dba of SciencePlusPlease LLC

Published under a Creative Commons Attribution-NonCommercial-NoDerivatives 4.0 International (CC BY-NC-ND) 4.0 International License (http://creativecommons.org/licenses/by-nc-nd/4.0/).

CSDSp-bioRxiv-wFigures\&SupplementalMaterial_210408.doc, scj, 4/8/2021 12:45 PM, ps1/ 49 
Hund et al. Scalp detection of cortical spreading depolarization from concussion Page 23 of 49

of the truly active system, where biofluidic pathways, i.e., blood and CSF, may serve to restore voltage potentials more efficiently than a passive material. For example, blood flow can increase post-SD [38] and may remove excess ions [106; page 156]. In addition, massive amounts of $\mathrm{K}^{+}$ appear in the CSF [107] and their clearance via the glymphatic route [108] could alter the voltage potential.

\subsection{Estimated Surface Characteristics and Voltage Ratio - Comparison of Simulated Square and Triangle Waves}

The simulated DC-potential on the scalp has identifiable shape and magnitude characteristics. The spatial extent of the voltage change due to the SD wave expands considerably, from $2.4 \mathrm{~mm}$ to $30.8 \mathrm{~mm}$, as it passes through tissue, allowing it to be detected by multiple electrodes simultaneously. The voltage data presented here are discussed in terms of $\mathrm{V}_{\text {ratio}}$, the peak scalp electrode sampled voltage scaled by the peak voltage of the SD. The simulation predicted voltage ratios of 0.18 and 0.0735 for the square wave and triangular wave, respectively. Aesthetically, the triangle wave offers a better fit to the waveforms observed by Drenckhahn et al. [31]. The primary reason that the square wave shows better propagation of voltage (higher $|\mathrm{V}|)$ is that it produces more power $\left(\mathrm{V}^{2} / \mathrm{R}\right)$ for a given resistance.

\subsection{Comparison of Voltage Ratios - Simulation vs. Clinical Research}

The median value of the voltage ratio from the retrospective analysis of data from Drenckhahn et al. [31] was $0.0316(0.0221,0.0527)$, which is significantly different from our voltage ratio value of $0.0735(\mathrm{p}<0.001)$. This difference is within the same general range and is acceptable for our purposes, especially because data from human concussive SDs is not available. The higher voltage ratio from our simulation of an expanding ring concussive SD can 
Hund et al. Scalp detection of cortical spreading depolarization from concussion Page 24 of 49

be attributed to the different shape, size, and propagating configuration of its electric field as compared to that of an aSAH SD. While an aSAH SD is limited in spatial extent to a few or slightly more millimeters, the SD of a concussive ring grows in spatial extent on the cortex. Therefore, the strength of signal predicted at the scalp surface is stronger for the expanding ring. Analytic models of the expanding ring SD and an aSAH SD-like 'blob' model were compared. The blob-SD had a triangular voltage profile with a width of $3 \mathrm{~mm}$. These analytic models allow predictions of the scalp surface DC-voltage ratios, which are 0.093 for the expanding ring, compared to 0.010 for the 'blob' model with triangular waveform. This analysis explains why our simulated concussive SD voltage ratio of 0.0735 is much larger than the ratio from our retrospective data analysis of human aSAH SDs. Furthermore, there are inherent limitations in calculating a ratio of human voltage measurements due to misalignment of the subdural electrode strip and the scalp electrodes. There are also complications in the estimation of an SD's maximum voltage as sensed by a limited one-dimensional ECoG electrode array and the widely separated scalp EEG electrodes in relation to an SD’s trajectory.

\subsection{SD Detectability}

Because the conductivity equation is linear and material properties are constant, the relative voltage is independent of the peak voltage $\left(\Delta \mathrm{V}_{\mathrm{SD}}\right)$, but not the voltage waveform used to model the SD. Therefore, a single numerical experiment can be used to evaluate a full range of voltages. If we apply our simulated triangle wave voltage ratio of 0.0735 to the minimum voltage of the retrospectively determined brain-surface voltages from Drenckhahn et al. [31] of -800 $\mu \mathrm{V}$, we obtain an estimated scalp voltage of $-59 \mu \mathrm{V}$. This voltage is within the sensitivity threshold of currently available DC-coupled biosignal amplifiers. This suggests that the threshold of 
Hund et al. Scalp detection of cortical spreading depolarization from concussion Page 25 of 49

sensitivity for DC-EEG is an important consideration and that all but the weakest scalp voltages from a SD would be detectable.

\subsection{Limitations}

The SD spreads uniformly in the simulation since there is no biochemical, physical, or anatomical variation in the simulated (lissencephalic) cortex [109, 110] or in the modeled material layers that would serve to distort the shape of the wave. Modeling and observational studies of SD propagation patterns in a gyrencephalic cortex have not dealt with the DCpotentials associated with SDs nor with their detectability [110-112] as these aspects represent a difficult modeling challenge. However, the simulation suggests the design parameters of a preliminary sensor array can be used to obtain the experimental results necessary to refine the numerical model and SD detection algorithms that could be developed for such a scalp SD sensor unit. Another limitation of this current study is that the effect of local drift such as the TEP $[113,114]$ and noise resulting from improper electrode-skin contact were not included.

A sensor array with electrode spacings of $1.0 \mathrm{~cm}$ is sufficient to reconstruct a concentrically spreading SD without noise on the scalp of a patient. Obviously, the addition of large-scale background noise will hinder the reconstruction of the signal, as will the local failure of a single electrode depending on the overall effectiveness of the algorithms used to process the incoming signals. Other issues to be considered include the relative electrode sensor sensitivities and relative motion to the scalp.

\subsection{Conclusion}

This simulation study suggests that propagating SDs can be detected on the scalp with properly configured DC-EEG. If our simulation results were used to implement successful non-invasive

Copyright $\odot 2021$ All rights reserved, CerebroScope, the dba of SciencePlusPlease LLC

Published under a Creative Commons Attribution-NonCommercial-NoDerivatives 4.0 International (CC BY-NC-ND) 4.0 International License (http://creativecommons.org/licenses/by-nc-nd/4.0/).

CSDSp-bioRxiv-wFigures\&SupplementalMaterial_210408.doc, scj, 4/8/2021 12:45 PM, ps1/ 49 
Hund et al. Scalp detection of cortical spreading depolarization from concussion Page 26 of 49

SD scalp detection, the link between SD and concussion could be confirmed. The confirmation of this link would involve a large clinical trial using a deployable non-invasive SD detection system that could be placed on an athlete's head 30-50 minutes after a suspected concussion. SD could then provide a unifying concept for the wide-ranging symptoms of concussion; the varying symptoms used to diagnose concussion could be a result of SD occurring in different cortical locations, depending on where the head-hit occurred. In addition, our results imply that the noninvasive detectability of SDs in severe acute brain injury patients in the Neurointensive Care Unit is dependent on the proper electrode array configuration. 
Hund et al. Scalp detection of cortical spreading depolarization from concussion Page 27 of 49

Acknowledgements We thank Thomas Ferguson, Richard Kraig, Douglas Smith, and Joel Greenberg for reading and commenting on the manuscript and Hiba Al-Ashtal for editorial services.

Funding Information This project was conducted for CerebroScope, a medical device company developing a scalp DC-EEG system for detecting SDs in severe acute brain injury, concussion, and migraine. This work was partially supported by grants from the: US Public Health Service National Institutes of Health: NS30839; NS30839-14S1; and NS66292 to the SCJ while at the Allegheny-Singer Research Institute; and 5R43NS092181 and 3R43NS092181-02S1 to SCJ for CerebroScope; DFG Deutsche Forschungsgemeinschaft, German Research Council: DFG DR 323/5-1 and DFG DR 323/10-1 to JPD; and BMBF Bundesministerium fuer Bildung und Forschung (Era-Net Neuron EBio2), with funds from BMBF (0101EW2004) to JPD.

Compliance with Ethical Standards All ethical standards have been met. See section "Retrospective Evaluation of Human Data”.

Competing interests Samuel J. Hund, Prahlad G. Menon, and Stephen C. Jones are founding partners and shareholders of CerebroScope. Benjamin R. Brown is a consultant to and shareholder of CerebroScope.

Intellectual Property Disclosures Parts of this work are disclosed in U.S. Patent No. 10,028,694, issued July 24, 2018; and in U.S. Published Patent Application No. 2019/0038167, published February 7, 2019. 
Hund et al. Scalp detection of cortical spreading depolarization from concussion Page 28 of 49

\section{References}

1. Langlois JA, Rutland-Brown W, Wald MM. The epidemiology and impact of traumatic brain injury: a brief overview. J Head Trauma Rehabil. 2006;21:375-378.

2. Coronado VG, McGuire LC, Sarmiento K et al. Trends in Traumatic Brain Injury in the U.S. and the public health response: 1995-2009. J Safety Res. 2012;43:299-307.

3. Lefevre-Dognin C, Cogné M, Perdrieau V, Granger A, Heslot C, Azouvi P. Definition and epidemiology of mild traumatic brain injury. Neurochirurgie. 2020; Online ahead of print: https://doi.org/10.1016/j.neuchi.2020.02.002.

4. Mansell JL, Tierney RT, Higgins M, McDevitt J, Toone N, Glutting J. Concussive signs and symptoms following head impacts in collegiate athletes. Brain Inj. 2010;24:10701074.

5. Costello DM, Kaye AH, O'Brien TJ, Shultz SR. Sport related concussion - Potential for biomarkers to improve acute management. J Clin Neurosci. 2018;56:1-6.

6. Davis GA, Ellenbogen RG, Bailes J et al. The Berlin International Consensus Meeting on Concussion in Sport. Neurosurgery. 2018;82:232-236.

7. Master CL, Mayer AR, Quinn D, Grady MF. Concussion. Ann Intern Med. 2018;169:ITC1-ITC16 (https://doi.org/10.7326/AITC201807030).

8. Provencher MT, Frank RM, Shubert DJ, Sanchez A, Murphy CP, Zafonte RD. Concussions in Sports. Orthopedics. 2019;42:12-21.

9. Hobbs JG, Young JS, Bailes JE. Sports-related concussions: diagnosis, complications, and current management strategies. Neurosurg Focus. 2016;40:E5: https://doi.org/10.3171/2016.1.FOCUS15617.

10. Shively SB, Perl DP. Traumatic brain injury, shell shock, and posttraumatic stress disorder in the military--past, present, and future. J Head Trauma Rehabil. 2012;27:234239. 
Hund et al. Scalp detection of cortical spreading depolarization from concussion Page 29 of 49

11. Wells TS, Miller SC, Adler AB, Engel CC, Smith TC, Fairbank JA. Mental health impact of the Iraq and Afghanistan conflicts: a review of US research, service provision, and programmatic responses. Int Rev Psychiatry. 2011;23:144-152.

12. Guskiewicz KM, Marshall SW, Bailes J et al. Association between recurrent concussion and late-life cognitive impairment in retired professional football players. Neurosurgery. 2005;57:719-726.

13. Harmon KG, Drezner JA, Gammons M et al. American Medical Society for Sports Medicine position statement: concussion in sport. Br J Sports Med. 2013;47:15-26.

14. Bruce J, Echemendia R, Meeuwisse W, Comper P, Sisco A. 1 year test-retest reliability of ImPACT in professional ice hockey players. Clin Neurophysiol. 2013;28:14-25.

15. Lichtenstein JD, Moser RS, Schatz P. Age and Test Setting Affect the Prevalence of Invalid Baseline Scores on Neurocognitive Tests. Am J Sports Med. 2013;42:479-484.

16. Resch J, Driscoll A, McCaffrey N et al. ImPact Test-Retest Reliability: Reliably Unreliable? J Athl Train. 2013;48:506-511.

17. Barlow M, Schlabach D, Peiffer J, Cook C. Differences in change scores and the predictive validity of three commonly used measures following concussion in the middle school and high school aged population. Inter J Sports Phys Ther. 2011;6:150-157.

18. McClure DJ, Zuckerman SL, Kutscher SJ, Gregory AJ, Solomon GS. Baseline Neurocognitive Testing in Sports-Related Concussions: The Importance of a Prior Night's Sleep. Am J Sports Med. 2014;42:472-478.

19. Cole WR, Arrieux JP, Schwab K, Ivins BJ, Qashu FM, Lewis SC. Test-retest reliability of four computerized neurocognitive assessment tools in an active duty military population. Arch Clin Neuropsychol. 2013;28:732-742.

20. Thiagarajan P, Ciuffreda KJ, Ludlam DP. Vergence dysfunction in mild traumatic brain injury (mTBI): a review. Ophthalmic Physiol Opt. 2011;31:456-468.

21. Echemendia RJ, Putukian M, Mackin RS, Julian L, Shoss N. Neuropsychological test performance prior to and following sports-related mild traumatic brain injury. Clin $\mathrm{J}$ Sport Med. 2001;11:23-31.

Copyright $\odot 2021$ All rights reserved, CerebroScope, the dba of SciencePlusPlease LLC Published under a Creative Commons Attribution-NonCommercial-NoDerivatives 4.0 International (CC BY-NC-ND) 4.0 International License (http://creativecommons.org/licenses/by-nc-nd/4.0/). 
Hund et al. Scalp detection of cortical spreading depolarization from concussion Page 30 of 49

22. Echemendia RJ, Meeuwisse W, McCrory P et al. The Sport Concussion Assessment Tool 5th Edition (SCAT5): Background and rationale. Br J Sports Med. 2017;51:848-850.

23. Ochiai H, Abe T. Clinical features and early detection of sport-related concussion. Acute Med Surg. 2019;6:49-53.

24. Broglio SP, Cantu RC, Gioia GA et al. National Athletic Trainers' Association position statement: management of sport concussion. J Athl Train. 2014;49:245-265.

25. Somjen GG. Mechanisms of spreading depression and hypoxic spreading depression-like depolarization. Physiol Rev. 2001;81:1065-1096.

26. Pacheco JM, Hines-Lanham A, Stratton C et al. Spreading Depolarizations Occur in Mild Traumatic Brain Injuries and Are Associated with Postinjury Behavior. eNeuro. 2019;6:1-17.

27. Smith DH, Stewart W. 'Concussion' is not a true diagnosis. Nat Rev Neurol. 2020;16:457-458.

28. McCuddy WT, España LY, Nelson LD, Birn RM, Mayer AR, Meier TB. Association of acute depressive symptoms and functional connectivity of emotional processing regions following sport-related concussion. Neuroimage Clin. 2018;19:434-442.

29. O'Jile JR, Ryan LM, Betz B et al. Information processing following mild head injury. Arch Clin Neuropsychol. 2006;21:293-296.

30. Leao AA. The slow voltage variation of cortical spreading depression of activity. Electroencephalogr Clin Neurophysiol. 1951;3:315-321.

31. Drenckhahn C, Winkler MK, Major S et al. Correlates of spreading depolarization in human scalp electroencephalography. Brain. 2012;135:853-868.

32. Lauritzen M, Dreier JP, Fabricius M, Hartings JA, Graf R, Strong AJ. Clinical relevance of cortical spreading depression in neurological disorders: migraine, malignant stroke, subarachnoid and intracranial hemorrhage, and traumatic brain injury. J Cereb Blood Flow Metab. 2011;31:17-35.

33. Strong AJ, Fabricius M, Boutelle MG et al. Spreading and synchronous depressions of cortical activity in acutely injured human brain. Stroke. 2002;33:2738-2743. 
Hund et al. Scalp detection of cortical spreading depolarization from concussion Page 31 of 49

34. Leao AAP. Further observations on the speading depression of activity in the cerebral cortex. J Neurophysiol. 1947; 10:409-414.

35. Kraig RP, Nicholson C. Extracellular ionic variations during spreading depression. Neuroscience. 1978;3:1045-1059.

36. Dreier JP. The role of spreading depression, spreading depolarization and spreading ischemia in neurological disease. Nat Med. 2011;17:439-447.

37. Enger R, Tang W, Vindedal GF et al. Dynamics of Ionic Shifts in Cortical Spreading Depression. Cereb Cortex. 2015;25:4469-4476.

38. Woitzik J, Hecht N, Pinczolits A et al. Propagation of cortical spreading depolarization in the human cortex after malignant stroke. Neurology. 2013;80:1095-1102.

39. Leao AAP. Spreading depression of activity in the cerebral cortex. J Neurophysiol. 1944;7:359-390.

40. Grafstein B. Locus of propagation of spreading cortical depression. J Neurophysiol. 1956;19:308-316.

41. Mayevsky A, Doron A, Manor T, Meilin S, Zarchin N, Ouaknine GE. Cortical spreading depression recorded from the human brain using a multiparametric monitoring system. Brain Res. 1996;740:268-274.

42. Dohmen C, Sakowitz OW, Fabricius M et al. Delayed secondary phase of peri-infarct depolarizations after focal cerebral ischemia: relation to infarct growth and neuroprotection. Ann Neurol. 2008;63:720-728.

43. Dreier JP, Woitzik J, Fabricius M et al. Delayed ischaemic neurological deficits after subarachnoid haemorrhage are associated with clusters of spreading depolarizations. Brain. 2006;129:3224-3237.

44. Dreier JP, Major S, Manning A et al. Cortical spreading ischaemia is a novel process involved in ischaemic damage in patients with aneurysmal subarachnoid haemorrhage. Brain. 2009;132:1866-1881.

45. Fabricius M, Fuhr S, Bhatia R et al. Cortical spreading depression and peri-infarct depolarization in acutely injured human cerebral cortex. Brain. 2006;129:778-790. 
Hund et al. Scalp detection of cortical spreading depolarization from concussion Page 32 of 49

46. Hartings JA, Bullock MR, Okonkwo DO et al. Spreading depolarisations and outcome after traumatic brain injury: a prospective observational study. Lancet Neurol. 2011;10:1058-1064.

47. Helbok R, Schiefecker AJ, Friberg C et al. Spreading depolarizations in patients with spontaneous intracerebral hemorrhage: Association with perihematomal edema progression. J Cereb Blood Flow Metab. 2017;37:1871-1882.

48. Dreier JP, Reiffurth C. The stroke-migraine depolarization continuum. Neuron. 2015;86:902-922.

49. Hartings JA, Shuttleworth CW, Kirov SA et al. The continuum of spreading depolarizations in acute cortical lesion development: Examining Leao's legacy. J Cereb Blood Flow Metab. 2017;37:1571-1594.

50. Oliveira-Ferreira AI, Milakara D, Alam M et al. Experimental and preliminary clinical evidence of an ischemic zone with prolonged negative DC shifts surrounded by a normally perfused tissue belt with persistent electrocorticographic depression. J Cereb Blood Flow Metab. 2010;30:1504-1519.

51. Hartings JA, York J, Carroll CP et al. Subarachnoid blood acutely induces spreading depolarizations and early cortical infarction. Brain. 2017;140:2673-2690.

52. Luckl J, Lemale CL, Kola V et al. The negative ultraslow potential, electrophysiological correlate of infarction in the human cortex. Brain. 2018;141:1734-1752.

53. Dreier JP, Major S, Foreman B et al. Terminal spreading depolarization and electrical silence in death of human cerebral cortex. Ann Neurol. 2018;83:295-310.

54. Dreier JP, Major S, Lemale CL et al. Correlates of Spreading Depolarization, Spreading Depression, and Negative Ultraslow Potential in Epidural Versus Subdural Electrocorticography. Front Neurosci. 2019;13:373.

55. Carlson AP, Shuttleworth CW, Major S, Lemale CL, Dreier JP, Hartings JA. Terminal spreading depolarizations causing electrocortical silencing prior to clinical brain death: case report. J Neurosurg. 2018;131:1773-1779. 
Hund et al. Scalp detection of cortical spreading depolarization from concussion Page 33 of 49

56. Hadjikhani N, Sanchez Del Rio M, Wu O et al. Mechanisms of migraine aura revealed by functional MRI in human visual cortex. Proc Natl Acad Sci USA. 2001;98:4687-4692.

57. Major S, Huo S, Lemale CL et al. Direct electrophysiological evidence that spreading depolarization-induced spreading depression is the pathophysiological correlate of the migraine aura and a review of the spreading depolarization continuum of acute neuronal mass injury. Geroscience. 2020;42:57-80.

58. Kumagai T, Walberer M, Nakamura H et al. Distinct spatiotemporal patterns of spreading depolarizations during early infarct evolution: evidence from real-time imaging. $\mathrm{J}$ Cereb Blood Flow Metab. 2011;31:580-592.

59. Zachar J, Zacharova D. [Mechanical energy as causative agent of spreading depression]. Cesk Fysiol. 1958;7:189-190.

60. Zachar J, Zacharova D. [Mechanism of the origin of spreading cortical depression] (in Slovak). Lek Pr. 1963;3:3-110.

61. Zachar J, Zacharova D. Subthreshold changes at the site of initiation of spreading cortical depression by mechanical stimuli. Electroencephalogr Clin Neurophysiol. 1961;13:896904.

62. Bures J, Buresova O, Krivanek J. Initiation of Spreading Depression: Mechanical Stimuli. The Mechanism and Application of Leao's Spreading Depression of Electroencephalographic Activity. Prague: Academia; 1974:26-30.

63. Shah KR, West M. The effect of concussion on cerebral uptake of 2-deoxy-D-glucose in rat. Neurosci Lett. 1983;40:287-291.

64. Takahashi H, Manaka S, Sano K. Changes in extracellular potassium concentration in cortex and brain stem during the acute phase of experimental closed head injury. $\mathrm{J}$ Neurosurg. 1981;55:708-717.

65. West M, Parkinson D, Havlicek V. Spectral analysis of the electroencephalographic response in experimental concussion in the rat. Electroencephalogr Clin Neurophysiol. 1982;53:192-200. 
Hund et al. Scalp detection of cortical spreading depolarization from concussion Page 34 of 49

66. Meyer JS, Denny-Brown D. Studies of cerebral circulation in brain injury. II. Cerebral concussion. Electroencephalogr Clin Neurophysiol. 1955;7:529-544.

67. Watanabe N, Noriaki W. The Mechanism and Pathophysiology of Rat Cerebral Concussion: Changes in rCBF, ECoG, SPC Following Skull Impact. Journal of the Medical Society of Toho University. 2002;49:23-30.

68. Bouley J, Chung DY, Ayata CY, Brown RH, Jr., Henninger N. Cortical spreading depression denotes concussion injury. J Neurotrauma. 2019;36:1008-1017.

69. Oka H, Kako M, Matsushima M, Ando K. Specific type of head injury in children. Report of 5 cases. Brain. 1977;100:287-298.

70. Takahashi H, Nakazawa S. Specific type of head injury in children. Report of 5 cases. Childs Brain. 1980;7:124-131.

71. Barkhoudarian G, Hovda DA, Giza CC. The molecular pathophysiology of concussive brain injury. Clin Sports Med. 2011;30:33-48.

72. Sakas DE, Whitwell HL. Neurological episodes after minor head injury and trigeminovascular activation. Med Hypotheses. 1997;48:431-435.

73. The editor. Vasodilatation and migraine. Lancet.335[8693], 822-823. 4-7-1990.

74. Pietrobon D, Moskowitz MA. Chaos and commotion in the wake of cortical spreading depression and spreading depolarizations. Nat Rev Neurosci. 2014;15:379-393.

75. Marshall WH. Spreading cortical depression of Leao. Physiol Rev. 1959;39:239-279.

76. Geddes-Klein DM, Schiffman KB, Meaney DF. Mechanisms and consequences of neuronal stretch injury in vitro differ with the model of trauma. J Neurotrauma. 2006;23:193-204.

77. Keating CE, Cullen DK. Mechanosensation in traumatic brain injury. Neurobiol Dis. 2021;148:105210.

78. Tavalin SJ, Ellis EF, Satin LS. Mechanical perturbation of cultured cortical neurons reveals a stretch-induced delayed depolarization. J Neurophysiol. 1995;74:2767-2773.

Copyright $\odot 2021$ All rights reserved, CerebroScope, the dba of SciencePlusPlease LLC

Published under a Creative Commons Attribution-NonCommercial-NoDerivatives 4.0 International (CC BY-NC-ND) 4.0 International License (http://creativecommons.org/licenses/by-nc-nd/4.0/).

CSDSp-bioRxiv-wFigures\&SupplementalMaterial_210408.doc, scj, 4/8/2021 12:45 PM, ps1/ 49 
Hund et al. Scalp detection of cortical spreading depolarization from concussion Page 35 of 49

79. Hibino M, Itoh H, Kinosita K, Jr. Time courses of cell electroporation as revealed by submicrosecond imaging of transmembrane potential. Biophys J. 1993;64:1789-1800.

80. Fischer P, Sugimoto K, Chung DY et al. Rapid hematoma growth triggers spreading depolarizations in experimental intracortical hemorrhage. J Cereb Blood Flow Metab. 2020; Online ahead of print: https://doi.org/10.1177/0271678X20951993.

81. Hallez H, Vanrumste B, Grech R et al. Review on solving the forward problem in EEG source analysis. J Neuroeng Rehabil. 2007;4:https://doi.org/10.1186/1743-0003-4-46.

82. Ramon C, Schimpf PH, Haueisen J. Influence of head models on EEG simulations and inverse source localizations. BioMed Eng OnLine. 2006;5:1-13.

83. Miller JW, Kim W, Holmes MD, Vanhatalo S. Ictal localization by source analysis of infraslow activity in DC-coupled scalp EEG recordings. Neuroimage. 2007;35:583-597.

84. Cuffin BN. Effects of local variations in skull and scalp thickness on EEG's and MEG's. IEEE Trans Biomed Eng. 1993;40:42-48.

85. Cuffin BN. Effects of head shape on EEG's and MEG's. IEEE Trans Biomed Eng. 1990;37:44-52.

86. Stavtsev AI, Ushakov VL, Verkhliutov VM. [Modeling the effect of the layer thickness and tissue conductivities of the head and the brain on the EEG potentials using finite element method]. Zh Vyssh Nerv Deiat Im I P Pavlova. 2007;57:742-752.

87. Baillet S, Mosher JC, Leahy RM. Electromagnetic brain mapping. IEEE Signal Processing Magazine. 2001;18:14-30.

88. Leahy RM, Mosher JC, Spencer ME, Huang MX, Lewine JD. A study of dipole localization accuracy for MEG and EEG using a human skull phantom. Electroencephalogr Clin Neurophysiol. 1998;107:159-173.

89. Wen P. The impact of inhomogeneous tissue anisotropy on potential distribution within head model. Australas Phys Eng Sci Med. 2003;26:115-118.

90. Plis SM, George JS, Jun SC, Ranken DM, Volegov PL, Schmidt DM. Probabilistic forward model for electroencephalography source analysis. Phys Med Biol. 2007;52:5309-5327. 
Hund et al. Scalp detection of cortical spreading depolarization from concussion Page 36 of 49

91. Penn JW, Bell EL. Electrical Parameter Values of Some Human Tissues in the Radiofrequency Radiation Range. 1978; Defense Technical Information Center, Report \# SAM-TR-78-38; https://apps.dtic.mil/sti/pdfs/ADA064202.pdf

92. Gabriel C, Peyman A, Grant EH. Electrical conductivity of tissue at frequencies below 1 MHz. Phys Med Biol. 2009;54:4863-4878.

93. Pellman EJ, Viano DC, Tucker AM, Casson IR. Concussion in professional football: location and direction of helmet impacts-Part 2. Neurosurgery. 2003;53:1328-1340.

94. Dannhauer M, Lanfer B, Wolters CH, Knosche TR. Modeling of the human skull in EEG source analysis. Hum Brain Mapp. 2011;32:1383-1399.

95. Petrov Y. Anisotropic spherical head model and its application to imaging electric activity of the brain. Phys Rev E Stat Nonlin Soft Matter Phys. 2012;86:011917-011917: https://10.1103/PhysRevE.86.011917.

96. Bruno P, Vatta F, Mininel S, Inchingolo P. Referenced EEG and head volume conductor model: geometry and parametrical setting. Conf Proc IEEE Eng Med Biol Soc. 2004;2:833-836.

97. Johnson G, Massoudi M, Rajagopal KR. Flow of a fluid-solid mixture between flat plates. Chemical Engineering Science. 1991;46:1713-1723.

98. Tallgren P, Vanhatalo S, Kaila K, Voipio J. Evaluation of commercially available electrodes and gels for recording of slow EEG potentials. Clin Neurophysiol. 2005;116:799-806.

99. Voipio J, Tallgren P, Heinonen E, Vanhatalo S, Kaila K. Millivolt-scale DC shifts in the human scalp EEG: evidence for a nonneuronal generator. J Neurophysiol. 2003;89:22082214.

100. Roache PJ. Verification and Validation in Computational Science and Engineering. Albuquerque, New Mexico: Hermosa Publishers; 1998.

101. Dreier JP, Fabricius M, Ayata C et al. Recording, analysis, and interpretation of spreading depolarizations in neurointensive care: Review and recommendations of the COSBID research group. J Cereb Blood Flow Metab. 2017;37:1595-1625. 
Hund et al. Scalp detection of cortical spreading depolarization from concussion Page 37 of 49

102. Voorhies JM, Cohen-Gadol A. Techniques for placement of grid and strip electrodes for intracranial epilepsy surgery monitoring: Pearls and pitfalls. Surg Neurol Int. 2013;4:98.

103. Hartings JA, Wilson JA, Hinzman JM et al. Spreading depression in continuous electroencephalography of brain trauma. Ann Neurol. 2014;76:681-694.

104. Hofmeijer J, van Kaam CR, van de Werff B, Vermeer SE, Tjepkema-Cloostermans MC, van Putten MJAM. Detecting Cortical Spreading Depolarization with Full Band Scalp Electroencephalography: An Illusion? Front Neurol. 2018;9: https://www.frontiersin.org/articles/10.3389/fneur.2018.00017/full.

105. Hartings JA, Ngwenya LB, Watanabe T, Foreman B. Commentary: Detecting Cortical Spreading Depolarization with Full Band Scalp Electroencephalography: An Illusion? Front Syst Neurosci. 2018;12: https://www.frontiersin.org/articles/10.3389/fnsys.2018.00019/full.

106. Bures J, Buresova O, Krivanek J. The Mechanism and Application of Leao's Spreading Depression of Electroencephalographic Activity. Prague: Academia; 1974.

107. Brinley FJ, Jr., Kandel ER, Marshall WH. Potassium outflux from rabbit cortex during spreading depression. J Neurophysiol. 1960;23:246-256.

108. Mestre H, Du T, Sweeney AM et al. Cerebrospinal fluid influx drives acute ischemic tissue swelling. Science. 2020;367: https://doi.org/10.1126/science.aax7171.

109. James MF, Smith MI, Bockhorst KH et al. Cortical spreading depression in the gyrencephalic feline brain studied by magnetic resonance imaging. J Physiol. 1999;519 Pt 2:415-425.

110. Santos E, Sanchez-Porras R, Sakowitz OW, Dreier JP, Dahlem MA. Heterogeneous propagation of spreading depolarizations in the lissencephalic and gyrencephalic brain. $\mathrm{J}$ Cereb Blood Flow Metab. 2017;37:2639-2643.

111. Dahlem MA, Graf R, Strong AJ et al. Two-dimensional wave patterns of spreading depolarization: Retracting, re-entrant, and stationary waves. Physica D. 2010;239:889903. 
Hund et al. Scalp detection of cortical spreading depolarization from concussion Page 38 of 49

112. Kenny A, Plank MJ, David T. The effects of cerebral curvature on cortical spreading depression. J Theor Biol. 2019;472:11-26.

113. Picton TW, Hillyard SA. Cephalic skin potentials in electroencephalography. Electroencephalogr Clin Neurophysiol. 1972;33:419-424.

114. Tallgren P. DC-stable electrode-skin interface for human EEG recording. 2005; University of Helsinki, Department of Biological and Environmental Sciences, Finland: Report \# E5; http://lib.tkk.fi/Diss/2006/isbn9512269562/article4.pdf

115. Dahnke R, Yotter RA, Ziegler G, Gaser C. Brain Tissue Thickness Estimation using a Projection Scheme. 16th Annual Meeting of the Organization for Human Brain Mapping, Program \#1458; 2010 Jun 6; Barcelona: Organization of Human Brain Mapping; https://www.researchgate.net/profile/Robert_Dahnke/publication/336513396_Brain_Tiss ue_Thickness_Estimation_Using_a_Projection_Scheme/links/5da45dde45851553ff8f658 d/Brain-Tissue-Thickness-Estimation-Using-a-Projection-Scheme.pdf.

116. Bashkatov AN, Genina EA, Sinichkin YP, Kochubey VI, Lakodina NA, Tuchin VV. Glucose and mannitol diffusion in human dura mater. Biophys J. 2003;85:3310-3318.

117. Mahinda HAM, Murty OP. Variability in thickness of human skull bones and sternum An autopsy experience. J Forensic Med Toxicol. 2009;26:26-31.

118. Seery GE. Surgical anatomy of the scalp. Dermatol Surg. 2002;28:581-587.

119. Hori H, Moretti G, Rebora A, Crovato F. The thickness of human scalp: normal and bald. J Invest Dermatol. 1972;58:396-399. 
bioRxiv preprint doi: https://doi.org/10.1101/2021.04.08.438969; this version posted April 9, 2021. The copyright holder for this preprint (which

was not certified by peer review) is the author/funder, who has granted bioRxiv a license to display the preprint in perpetuity. It is made available under aCC-BY-NC-ND 4.0 International license.

Hund et al. Scalp detection of cortical spreading depolarization from concussion Page 39 of 49

\section{Table 1}

Table 1. The thickness, conductivity, and relative permittivity of each layer used to develop the computational model

\begin{tabular}{lllll}
\hline Material & Thickness & Conductivity & \multicolumn{2}{c}{ Relative Permittivity from } \\
\cline { 4 - 5 } & $(\mathbf{m m})$ & $(\mathbf{S} / \mathbf{m})$ & Penn and Bell [91] & Gabriel et al. [92] \\
\hline CSF & $0.50[115]$ & 2.00 & 79.5 & 109 \\
Dura Mater & $0.40[116]$ & 0.500 & 45.6 & $0.510 \mathrm{e} 6$ \\
Skull: Hard Bone & & 0.0200 & 5.61 & $55.2 \mathrm{e} 3$ \\
Skull: Soft Bone & & 0.0325 & 5.61 & $10.0 \mathrm{e} 6$ \\
Skull & & 0.0380 & 5.61 & \\
Muscle & $5.7[117]$ & 51.3 & $25.7 \mathrm{e} 6$ \\
Skin & $0.20[118]$ & 0.202 & 45.6 & 1136 \\
\hline
\end{tabular}

Source: See text for more details.

Conductivities estimated at $0 \mathrm{~Hz}$ from Gabriel et al. [92] and Penn and Bell [91]

CSF - Cerebrospinal fluid. 
bioRxiv preprint doi: https://doi.org/10.1101/2021.04.08.438969; this version posted April 9, 2021. The copyright holder for this preprint (which

was not certified by peer review) is the author/funder, who has granted bioRxiv a license to display the preprint in perpetuity. It is made available under aCC-BY-NC-ND 4.0 International license.

Hund et al. Scalp detection of cortical spreading depolarization from concussion Page 40 of 49

\section{Table 2}

Table 2. The peak voltage potential, relative voltage potential, and ring measurements at the interfaces between each material layer

\begin{tabular}{|c|c|c|c|c|c|c|c|}
\hline Layer & $\begin{array}{l}\left|V_{\max }\right| \\
(\mathrm{mV}) \\
\end{array}$ & $\begin{array}{c}V_{\text {ratio }} \\
(-) \\
\end{array}$ & $\begin{array}{c}\text { Ring } \\
\text { Thickness } \\
\text { (mm) } \\
\end{array}$ & $\begin{array}{c}\text { Ring } \\
\text { Radius } \\
(\mathbf{m m}) \\
\end{array}$ & $\begin{array}{c}\text { Maximum } \\
\text { Radius } \\
(\mathrm{mm}) \\
\end{array}$ & $\begin{array}{l}\text { Lag } 1 \\
(\mathrm{~mm}) \\
\end{array}$ & $\begin{array}{l}\text { Lag } 2 \\
(\mathrm{~mm}) \\
\end{array}$ \\
\hline Cortex & 20.0 & 1.00 & 2.40 & 45.2 & 45.2 & 0.00 & 0.00 \\
\hline CSF to DM & 14.9 & 0.747 & 2.80 & 45.2 & 45.2 & 0.00 & -0.001 \\
\hline DM to Skull & 9.89 & 0.495 & 3.85 & 45.2 & 45.2 & 0.025 & 0 \\
\hline Skull to Muscle & 1.71 & 0.0855 & 26.8 & 44.2 & 44.9 & 1.06 & 0.273 \\
\hline Muscle to Skin & 1.70 & 0.0848 & 27.0 & 44.2 & 44.9 & 1.07 & 0.294 \\
\hline Scalp & 1.47 & 0.0735 & 30.8 & 44.0 & 44.7 & 1.25 & 0.474 \\
\hline \multicolumn{8}{|c|}{$\begin{array}{l}\text { Data is shown after } 15 \text { minutes. } \\
\text { CSF - Cerebrospinal fluid } \\
\text { DM - Dura mater. } \\
\left|V_{\max }\right| \text { - The peak absolute voltage. } \\
V_{\text {ratio }} \text { - The relative voltage. } \\
\text { Ring Radius - The geometric or mean radius of the ring structure. } \\
\text { Maximum Radius - The radius at which the maximum absolute voltage occurs. } \\
\text { Lag } 1 \text { - The distance between the geometric ring radii at each layer to the ring radius of } \\
\text { Lag } 2 \text { - The distance between the Maximum Radius of the laver to that of the Cortex. }\end{array}$} \\
\hline
\end{tabular}

Copyright @ 2021 All rights reserved, CerebroScope, the dba of SciencePlusPlease LLC

Published under a Creative Commons Attribution-NonCommercial-NoDerivatives 4.0 International (CC BY-NC-ND) 4.0 International License (http://creativecommons.org/licenses/by-nc-nd/4.0/).

CSDSp-bioRxiv-wFigures\&SupplementalMaterial_210408.doc, scj, 4/8/2021 12:45 PM, ps1/ 49 
bioRxiv preprint doi: https://doi.org/10.1101/2021.04.08.438969; this version posted April 9, 2021. The copyright holder for this preprint (which

was not certified by peer review) is the author/funder, who has granted bioRxiv a license to display the preprint in perpetuity. It is made available under aCC-BY-NC-ND 4.0 International license.

Hund et al. Scalp detection of cortical spreading depolarization from concussion Page 41 of 49

\section{Figure Captions}

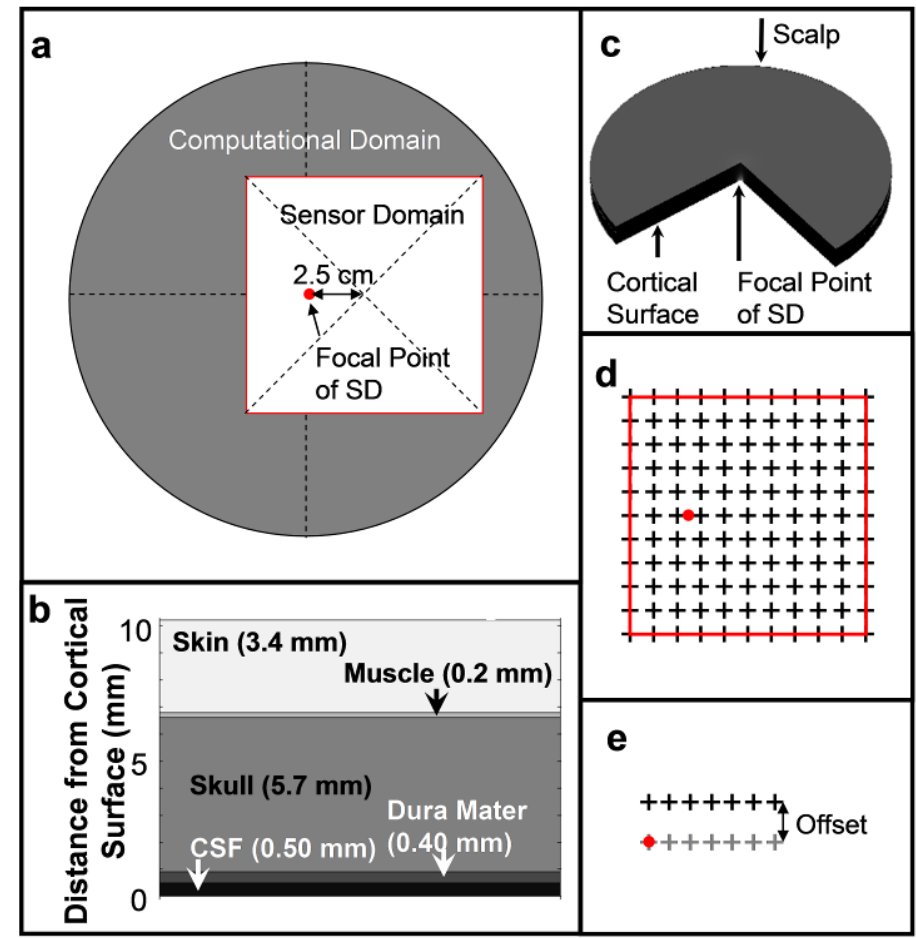

Fig. 1 The associated geometry and locations for the numerical analysis. a) The overlay of the 20-cm diameter computational domain (dark gray) and the sensor domain (white square with red border) showing the focal point of the spreading depolarization (SD) as a red dot. b) A slice view of the model layers with thickness representing cerebrospinal fluid (CSF), Dura Mater, Skull, Muscle, and Skin. c) The three-dimensional computational domain with a $90^{\circ}$ quadrant removed to show the layers and focal point of the SD. d) An example of the $10 \mathrm{~cm} \mathrm{x} 10 \mathrm{~cm}$ sensor grid (red border) with 1-cm spacing and electrode locations indicated by crosses and the focal point of the SD as a red dot. e) The sensor offset for velocity and geometric calculations with the ideal sensor position with gray crosses, an offset array in black, and the focal point of the SD as a red dot 
bioRxiv preprint doi: https://doi.org/10.1101/2021.04.08.438969; this version posted April 9, 2021. The copyright holder for this preprint (which was not certified by peer review) is the author/funder, who has granted bioRxiv a license to display the preprint in perpetuity. It is made available under aCC-BY-NC-ND 4.0 International license.

Hund et al. Scalp detection of cortical spreading depolarization from concussion Page 42 of 49

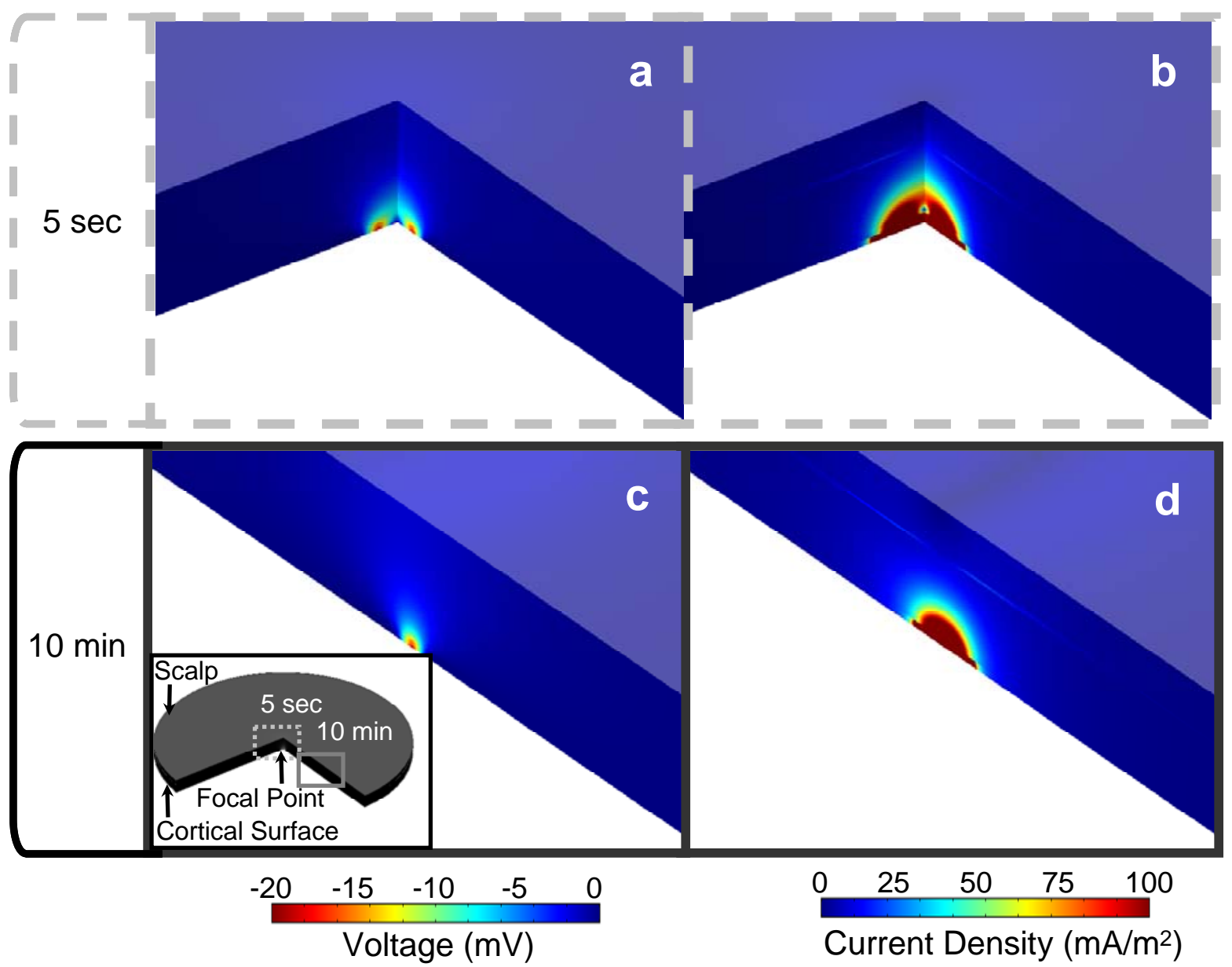

Fig. 2 Simulation results for electrical voltage and current density at $5 \mathrm{sec}$ and $10 \mathrm{~min}$ after spreading depolarization (SD) initiation in the 10-cm disk. Panels a and $\mathbf{b}$ (dashed border) show the numerical results at 5 seconds, and panels $\mathbf{c}$ and $\mathbf{d}$ (solid border) show them at 10 minutes after initiation of the SD for a concentrically spreading SD propagating radially. Panels a and c show the electrical potential (voltage in $\mathrm{mV}$ ), and panels $\mathbf{c}$ and $\mathbf{d}$ show the current density $\left(\mathrm{mA} / \mathrm{m}^{2}\right)$. The numerical pseudo-color scales for voltage and current density are shown below panels a and $\mathbf{c}$, and panels $\mathbf{b}$ and $\mathbf{d}$, respectively. The insert in panel $\mathbf{c}$ shows the relative location of the views of the SD depicted in panels $\mathbf{a}$ and $\mathbf{b}$ (5 seconds) as well as $\mathbf{c}$ and $\mathbf{d}$ (10 min). Also included in the insert are the location of the scalp, cortex, and focal point of the SD 
bioRxiv preprint doi: https://doi.org/10.1101/2021.04.08.438969; this version posted April 9, 2021. The copyright holder for this preprint (which was not certified by peer review) is the author/funder, who has granted bioRxiv a license to display the preprint in perpetuity. It is made available under aCC-BY-NC-ND 4.0 International license.

Hund et al. Scalp detection of cortical spreading depolarization from concussion Page 43 of 49

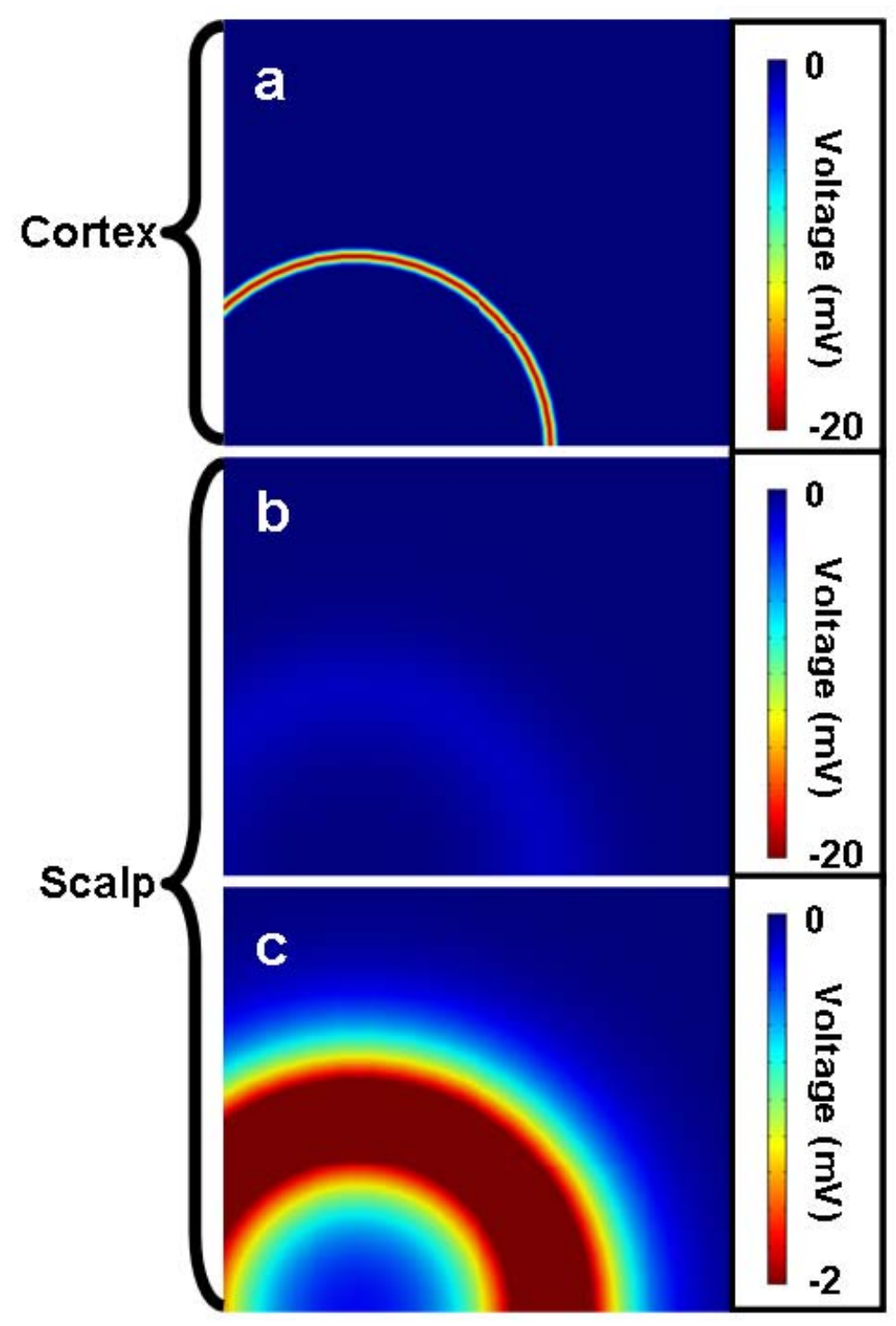

Fig. 3 The simulated voltage potential of a cortical spreading depolarization diminishes in amplitude at the scalp (b) but increases in effective width (c). The voltages in the cortex and scalp are shown with identical scales in (a) and (b) to highlight the change in amplitude. The scalp voltage map is rescaled in $\mathbf{c}$ to highlight the increase in ring diameter 
bioRxiv preprint doi: https://doi.org/10.1101/2021.04.08.438969; this version posted April 9, 2021. The copyright holder for this preprint (which was not certified by peer review) is the author/funder, who has granted bioRxiv a license to display the preprint in perpetuity. It is made available under aCC-BY-NC-ND 4.0 International license.

Hund et al. Scalp detection of cortical spreading depolarization from concussion Page 44 of 49

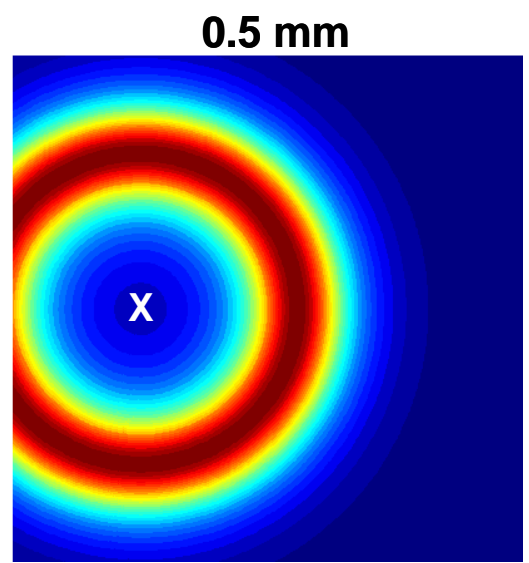

$20 \mathrm{~mm}$

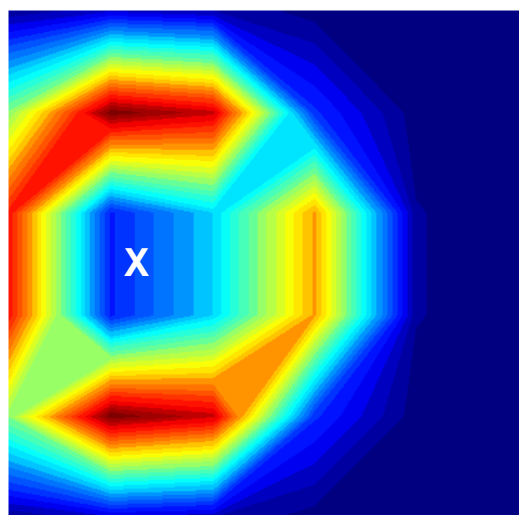

$5 \mathrm{~mm}$

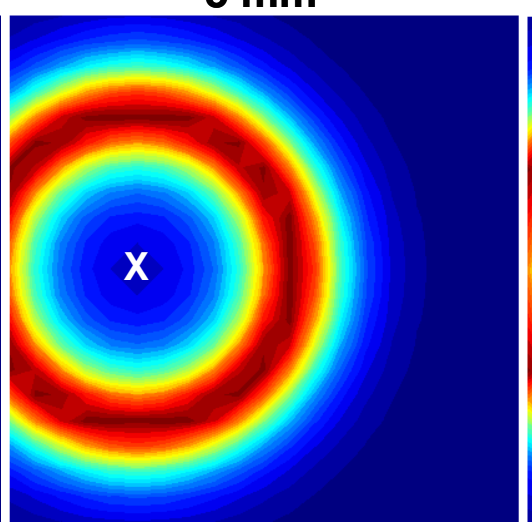

$30 \mathrm{~mm}$

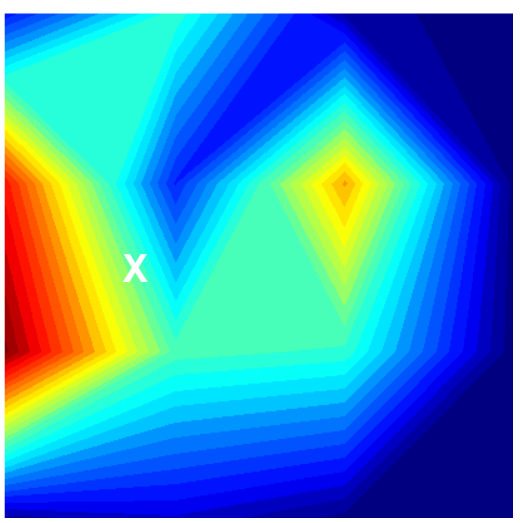

$10 \mathrm{~mm}$

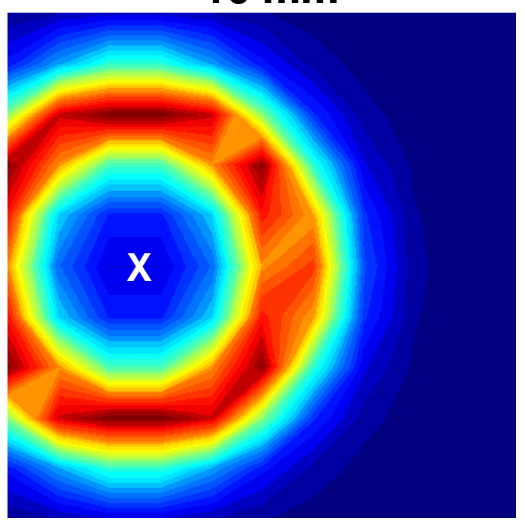

$0.0 \mathrm{mV}$

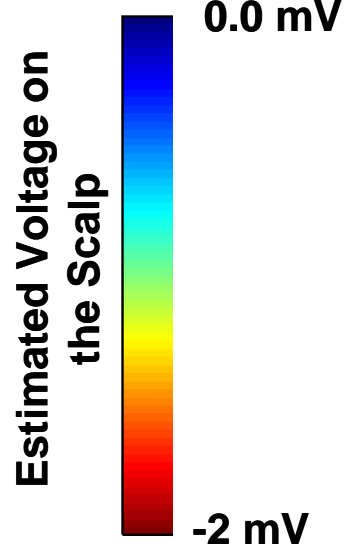

Fig. 4 The scalp voltage was sampled and reconstructed using simulated sensor grids with electrode spacings of $0.5,5,10,20$, and $30 \mathrm{~mm}$. These voltage maps represent the signal at 10 minutes after the onset of the spreading depolarization (SD). They illustrate the degradation of the reconstruction with increasing electrode spacing, and the preservation of the scalp voltage at electrode spacings of less than $1 \mathrm{~cm}$. The white $\mathrm{X}$ indicates the focal point of the SD. Reconstruction was performed using linear-linear interpolation between four electrodes 
Hund et al. Scalp detection of cortical spreading depolarization from concussion Page 45 of 49
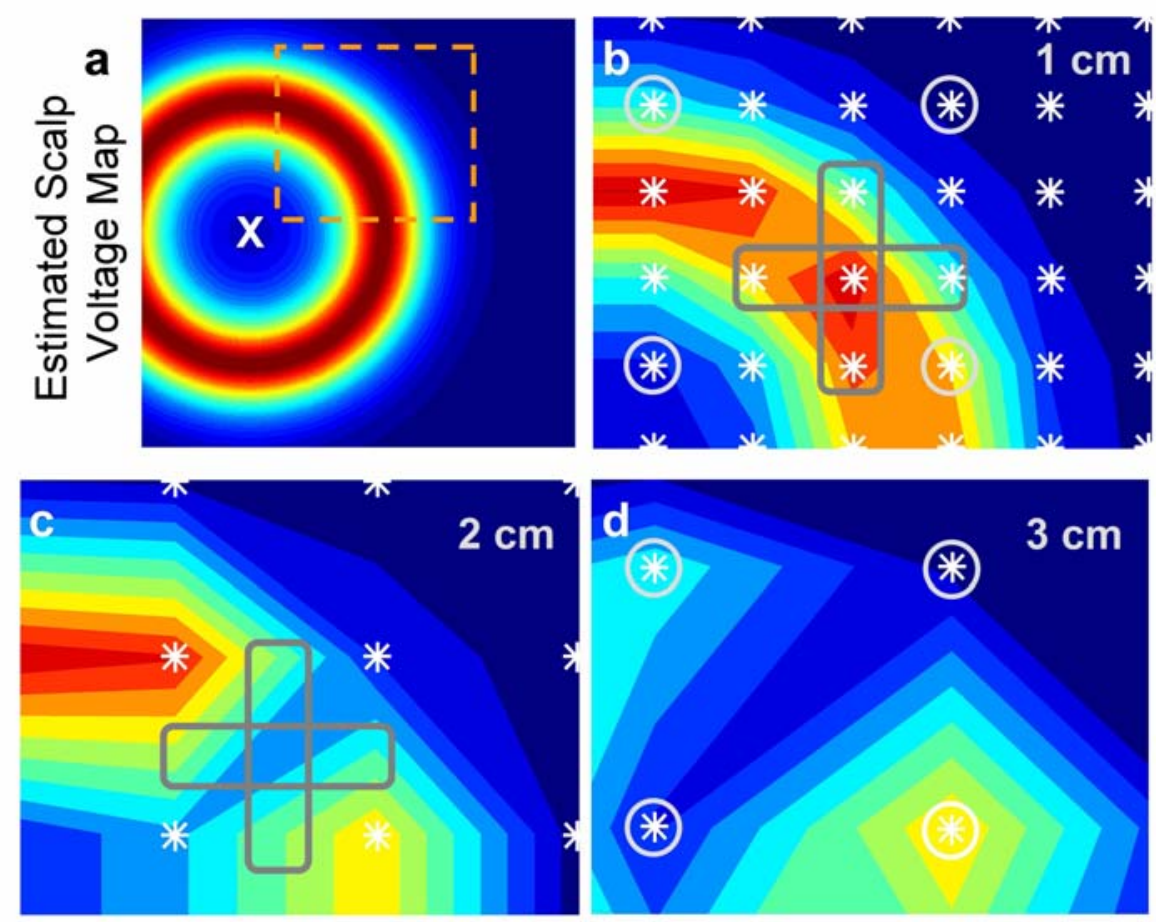

Estimated Voltage on the Scalp

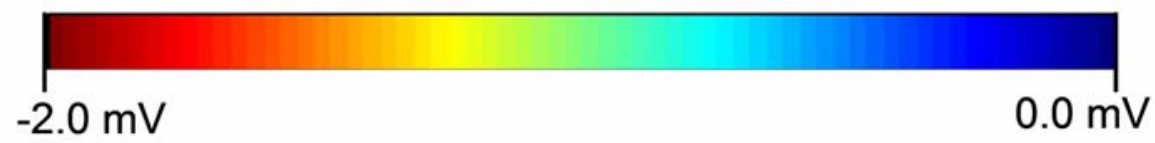

Fig. 5 Numerical simulation results of the scalp voltage reconstruction of a spreading depolarization (SD) expanding ring with different electrode spacings. (a) Estimated scalp voltage intensity map at $10 \mathrm{~min}$ after SD initiation in a $10 \mathrm{~cm}$ x $10 \mathrm{~cm}$ simulation domain. The symbol X marks the focal point of the SD on the underlying brain surface. The region within the dashed orange box is expanded to show the detail of the detected signal degradation with increased electrode spacing in (b), (c), and (d), with electrode spacings of 1, 2, and $3 \mathrm{~cm}$, respectively. Only the $1 \mathrm{~cm}$ spacing shows the full ring structure of the scalp voltage ( $2.5 \%$ error). The 2-cm sensor shows a recognizable ring but a low voltage wedge has broken the structure ( $15 \%$ error) (c). The 3-cm spacing fails to reconstruct the ring structure in the intensity map ( 25\% error) (d). The dark cross ( $\mathbf{b}$ and $\mathbf{c}$ ) indicates the locations of sensors that are removed from the $1 \mathrm{~cm}$ design to obtain the 2-cm design, which result in the breakdown of the ring. The white circles (b and $\mathbf{d}$ ) indicate the sensors from the 1-cm design that remain in the 3-cm array 
Hund et al. Scalp detection of cortical spreading depolarization from concussion Page 46 of 49

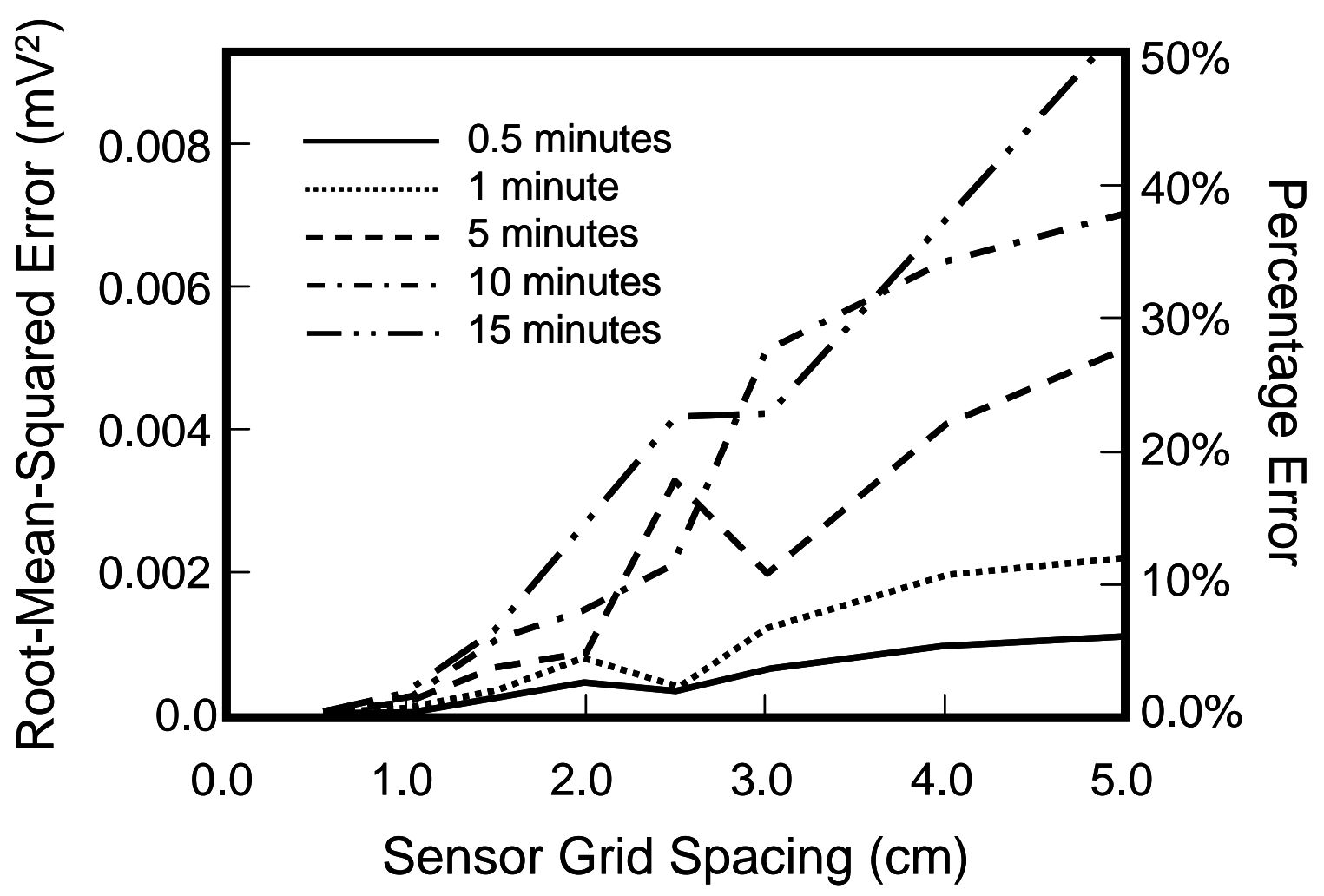

Fig. 6 The root-mean-squared error in the reconstruction, using the $0.05-\mathrm{cm}$ spacing as the baseline, for each of the sensor designs as a function of sensor electrode spacing and time. The error is reported at $0.5,1,5,10$, and 15 minutes 
bioRxiv preprint doi: https://doi.org/10.1101/2021.04.08.438969; this version posted April 9, 2021. The copyright holder for this preprint (which

was not certified by peer review) is the author/funder, who has granted bioRxiv a license to display the preprint in perpetuity. It is made available under aCC-BY-NC-ND 4.0 International license.

Hund et al. Scalp detection of cortical spreading depolarization from concussion Page 47 of 49

\section{Supplemental Material}

\section{For}

Numerical Simulation of Concussive-generated Cortical Spreading Depolarization to Optimize

EEG Electrode Spacing for Non-invasive Detection 
Hund et al. Scalp detection of cortical spreading depolarization from concussion Page 48 of 49

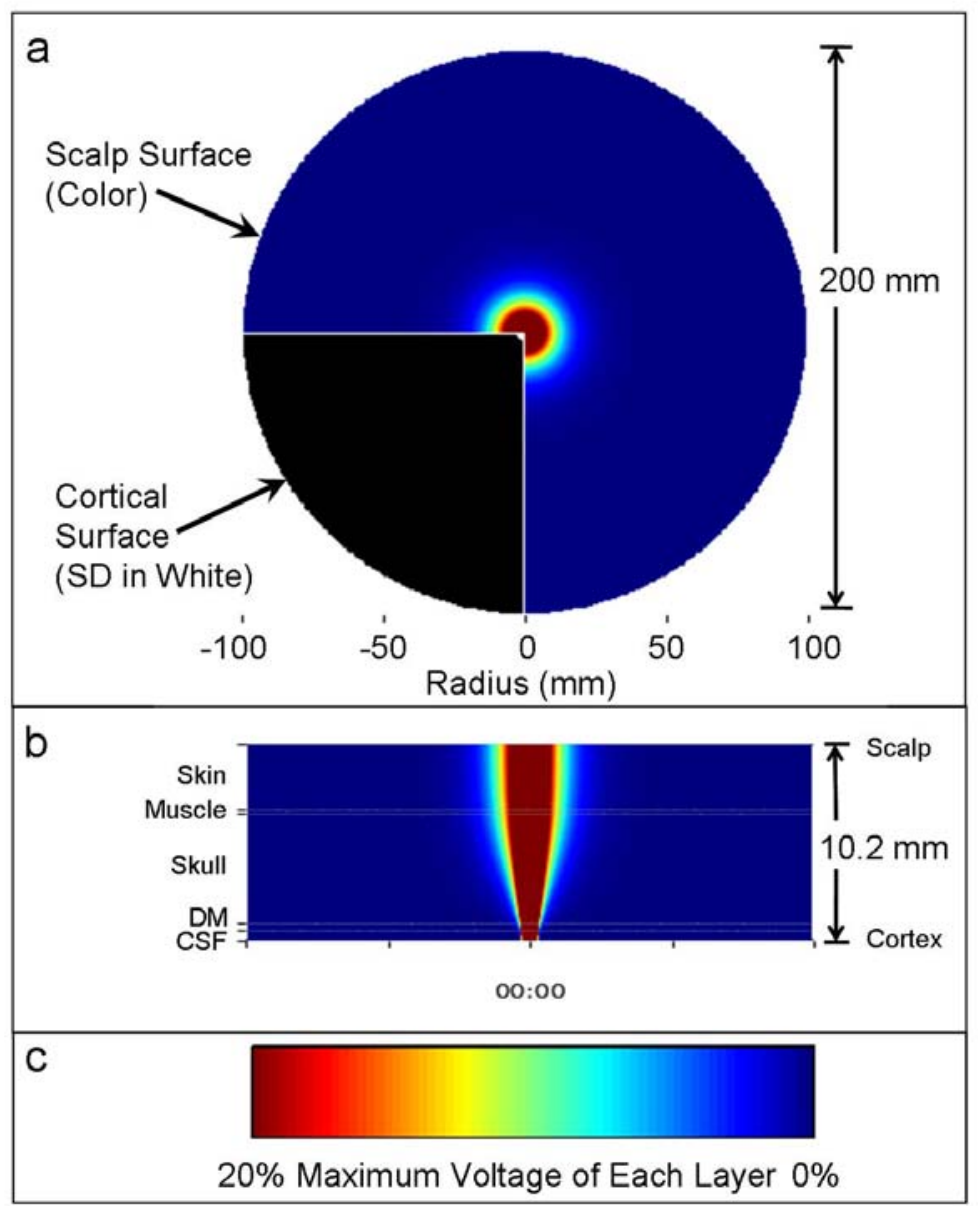

[Access Supplemental Movie 1, CSDSp_SupplementMaterial-Movie-S1_210406.mpg]

Supplemental Movie S1 Movie of a simulation of an expanding ring cortical Spreading Depolarization (SD) showing: (a) a top view of the simulated propagating scalp voltage, represented by a 200-mm diameter disk and mapped to the pseudo-color scale, between 5 seconds and 15 minutes from the concentrically expanding SD. The 3-mm wide, expanding ring SD on the cortical surface is shown in white against black in the lower left quadrant. (b) A radial section, or cross-section of a side view, showing the propagating SD through the 5 layers [skin, muscle, skull, dura mater (DM), and cerebrospinal fluid (CSF)] from the brain surface to the scalp (thickness $10.2 \mathrm{~mm}$ ) with a timer below. (c) The pseudo-color scale showing with the voltage scaled to $20 \%$ of the maximum voltage of each layer 
bioRxiv preprint doi: https://doi.org/10.1101/2021.04.08.438969; this version posted April 9, 2021. The copyright holder for this preprint (which was not certified by peer review) is the author/funder, who has granted bioRxiv a license to display the preprint in perpetuity. It is made available under aCC-BY-NC-ND 4.0 International license.

Hund et al. Scalp detection of cortical spreading depolarization from concussion Page 49 of 49

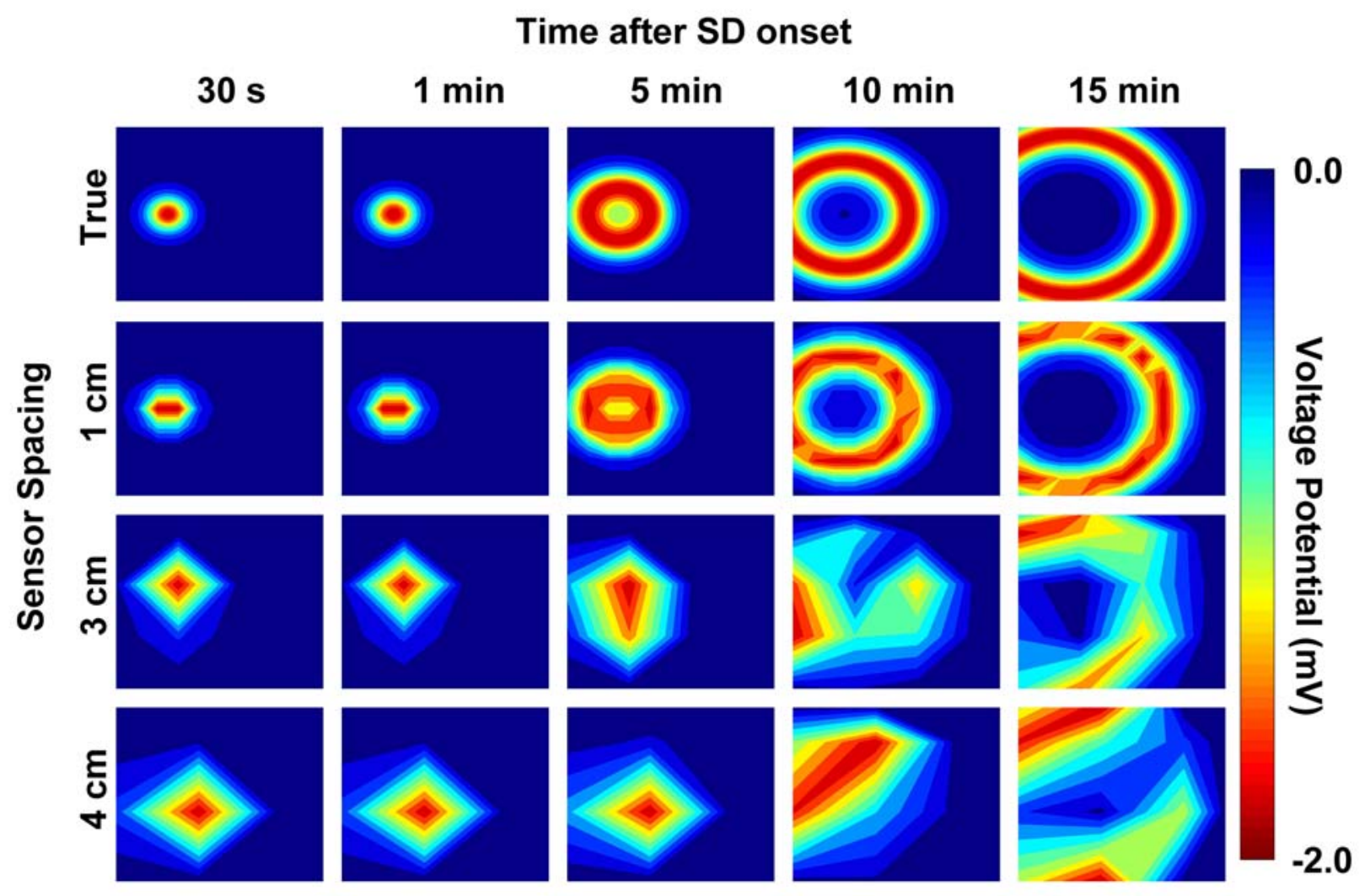

Supplemental Fig. $\mathbf{1}$ The scalp voltage intensity maps from a cortical spreading depolarization (SD) onset as a function of sensor spacing and time after onset. Top row: The exact voltage field is provided for reference at $0.5,1,5,10$, and 15 minutes after SD initiation. The bottom three rows show the simulated voltages at the scalp for the electrode spacings of 1,3 , and $4 \mathrm{~cm}$ 